\title{
Recent developments in Pd-catalyzed direct arylations of heteroarenes with aryl halides
}

\author{
FABIO BELLINA \\ Italy \\ fabio.bellina@unipi.it \\ 1 Introduction \\ 2 Direct arylations with aryl chlorides \\ 3 Blocking/activating removable functional groups \\ 4 Heterogeneous palladium catalysts \\ 5 Mild protocols for the direct arylation of heteroarenes \\ 6 Conclusions
}

Dipartimento di Chimica e Chimica Industriale, Università Di Pisa, I-56124 Pisa,

\begin{abstract}
The direct arylation of heteroaromatic compounds with aryl halides using palladium catalysts has significantly been developed as an effective method for making (hetero)arylheteroaryl bonds, which are frequently found in biologically active compounds and functional materials. However, issues regarding costly reagents, regioselectivity, and harsh reactions conditions have to be solved to really compete with the classical transition metal-mediated crosscoupling procedures involving stoichiometrical organometallic reagents. In this review the most relevant developments aimed at solving these issues are summarized.
\end{abstract}

Keywords Heteroarenes-Palladium catalysts-Regioselectivity-C-H bond activation-Arylation.

Abbreviations: Ad, 1-adamanthyl; Bn, Benzyl; Boc, tert-butoxycarbonyl ; Cy, cyclohexyl; DMF, dimethylformamide; DMA, dimethylacetamide; DMSO, dimethyl sulfoxide; dppe bis(diphenylphosphino)ethane; dppb, bis(diphenylphosphino)butane; NMP, N-methylpyrrolidone; SEM, 2(trimethylsilyl)ethoxymethyl.

\section{Introduction}

Arylheteroarenes represent important scaffolds in numerous biologically active compounds[1], and optical and photochromic materials in polymer sciences[2]. 
Due to their widespread applications, the development of straightforward functional group tolerant methods for their preparation has attracted organic chemist for over 100 years[3]. Although a variety of routes for the construction of the aryl-heteroaryl $\mathrm{Csp}^{2}-\mathrm{Csp}^{2}$ bond exist, probably the most general and effective methodology for the synthesis of (hetero)aryl-substituted heteroaromatics involves the use of transition metal-catalyzed cross-coupling reactions between (hetero)aryl halides and (hetero)aryl metal derivatives, including boronic acids, organozinc, organotin and organosilicon compounds, and Grignard reagents[3]. Although a number of improvements have been developed, and several industrial applications have been reported[4], the preactivation of both the coupling partners involves several manipulations prior the cross coupling, generating waste from reagents, solvents and purifications. Furthermore, a stoichionetric amount of metal waste is produced by the coupling process. In some cases, not all the regioisomers of the required organometallic reagents are readily available, or are too expensive to buy or synthesize, and in the worst cases they are too instable to participate in the coupling reaction. For all these reasons, there is urgency to continue the search for more efficient, regio- and chemoselective methods for the preparation of arylheteroarenes.

In recent years, the transition metal-catalyzed direct arylation of heteroaryl $\mathrm{C}-\mathrm{H}$ bonds with aryl halides emerged as an attractive, eco-friendly and economic alternative to traditional cross-coupling methods[5]. These reactions simply replace one of the preactivated coupling partners, the organometallic, with a simple heteroarene, reducing the metal waste generated in the overall process. In particular, electron-rich heteroarenes, such as azoles, constitute the "natural" replacements of heteroarylmetals in the catalytic cycles of these coupling reactions.

An early report of this approach, which contains examples of palladium-catalyzed direct arylation of isoxazole with iodobenzene, was published by Nakamura, Tajima and Sakai in 1982[6]. Since then, this chemistry has grown rapidly, in particular in the last decade, and a large variety of new, highly regioselective and synthetically useful direct inter- and intramolecular reactions involving five- and six-membered heteroarenes have been developed.

In this chapter it will be specifically examined some of the most relevant results in this field. In particular, the use of cheap aryl chlorides and of hetereogeneous 
palladium catalysts will be discussed. Some significant protocols for lowering reaction temperature and time, and for widening the scope by involving poorly reactive or unreactive heteroaromatic $\mathrm{C}$ - $\mathrm{H}$ bonds will be also summarized.

\section{Direct arylations of heteroarenes with aryl chlorides}

Significant progress has been made in the use of aryl chlorides as substrates in palladium-mediated cross-coupling reactions, and many reactions with aryl chlorides can now be performed under very mild conditions[7]. In contrast, direct arylation reactions employed aryl chlorides as substrates were rarely employed before 2005. In this year, Fagnou and co-workers described in an initial report the use of $N$-heterocyclic carbene (NHC) ligands for intramolecular direct arylation reactions with aryl chlorides [8], but in subsequent studies they found limitations when sterically hindered substrates were employed[9]. The authors then reinvestigated the intramolecular reaction of a broad range of heteroarenes with aryl iodides, bromides and chlorides. As regards chlorides, after a screening of bases and ligands, they found that in the presence of $5 \mathrm{~mol} \% \mathrm{Pd}(\mathrm{OAc})_{2}, 10 \mathrm{~mol} \%$ $\mathrm{PCy}_{3} \cdot \mathrm{HBF}_{4}, 2.0$ equiv of $\mathrm{K}_{2} \mathrm{CO}_{3}$ in DMA at $130{ }^{\circ} \mathrm{C}$ for $10 \mathrm{~h} 6 H$-isoindolo[2,1- $a$ ] was obtained in 78\% isolate yield starting from 1-(2-chlorobenzyl)-1H-indole (Scheme 1)[10].
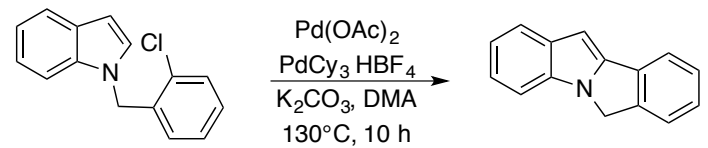

$(78 \%)$

Scheme 1. Synthesis of $6 H$-isoindolo[2,1-a] by intramolecular direct arylation with an aryl chloride

In 2006 Lecler and Fagnou reported the successful coupling of a molar excess of diazines $N$-oxides with aryl chlorides (Scheme 2)[11]. 

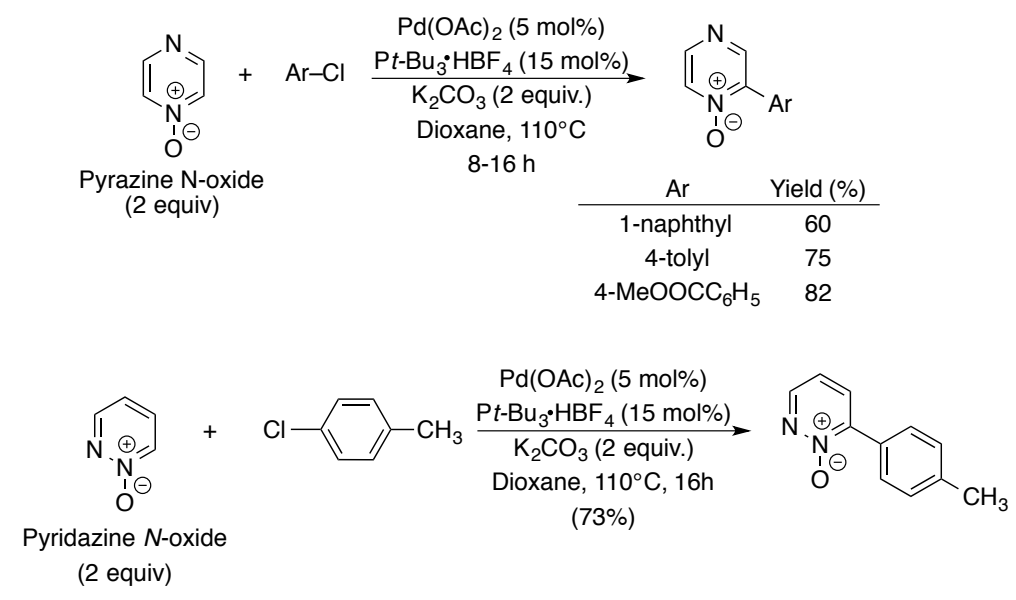

Scheme 2. Synthesis of 2-aryl substituted diazine $N$-oxides

In a competition study, the authors found that pyrazine $N$-oxide is approximately twice as reactive as pyridazine $N$-oxide. Pyrazine $N$-oxides may be deoxygenated with ammonium formate and $\mathrm{Pd} / \mathrm{C}$ in methanol at room temperature, giving the corresponding bases in excellent yields. However, this protocol resulted uncompatible with pyridazine $N$-oxide, and high yields were obtained when catalytic $\mathrm{Pd} / \mathrm{C}$ in ammonium hydroxide under an hydrogen atmosphere was employed.

During their studies on direct arylations involving azoles, Doucet and co-workers reported that aryl chlorides are able to react with 2-substituted thiazoles in the presence of $1 \mathrm{~mol} \%$ of the air stable $\mathrm{PdCl}_{2}(\mathrm{dppb})\left(\mathrm{C}_{6} \mathrm{H}_{5}\right)$ complex (Scheme 3)[12].

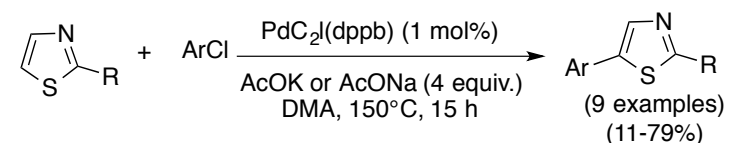

$$
\begin{aligned}
& \text { Ar: } 4-\mathrm{OHCC}_{6} \mathrm{H}_{4}, 4-\mathrm{MeOOCC}_{6} \mathrm{H}_{4}, 4-\mathrm{F}_{3} \mathrm{CC}_{6} \mathrm{H}_{4}, 4-\mathrm{NCC}_{6} \mathrm{H}_{4}, 4-\mathrm{O}_{2} \mathrm{NC}_{6} \mathrm{H}_{4}, 3-\mathrm{NCC}_{6} \mathrm{H}_{4} \text {, } \\
& 2-\mathrm{OHCC}_{6} \mathrm{H}_{4}, 2-\mathrm{F}_{3} \mathrm{CC}_{6} \mathrm{H}_{4}, 2-\mathrm{NCC}_{6} \mathrm{H}_{4}
\end{aligned}
$$

Scheme 3. Direct C5 arylation of 2-substituted thiazoles with aryl chlorides

Among the tested bases, $\mathrm{AcONa}$ and $\mathrm{AcOK}$ gave the best results, while alkali carbonates or KF resulted ineffective. The authors tried also the use of heterogeneous $\mathrm{Pd}(\mathrm{OH})_{2} / \mathrm{C}$ (Pearlman's catalyst) or $\mathrm{Pd} / \mathrm{C}$, but with poor results. As regards the precatalyst, "PdCl" resulted better than $\mathrm{Pd}(\mathrm{OAc})_{2}$, and dppb was superior as ligand in respect to dppe, dppf and the common monodentate ligand $\mathrm{PPh}_{3}$.

Due to the rapid attainment of high temperatures generally required for direct arylations, microwave irradiation represents an ideal strategy to shorten reaction time and, as a consequence, to increase chemical yields[13]. A microwave assisted palladium-catalyzed direct arylation of 1,4-disubstituted 1,2,3-triazoles with aryl chlorides was developed by Oshima and co-workers. In details, the 
treatment of 1,4-disubstituted 1,2,3-triazoles with aryl chlorides in the presence of 1.2 equiv of $\mathrm{K}_{2} \mathrm{CO}_{3}, 5 \mathrm{~mol} \% \mathrm{Pd}(\mathrm{OAc})_{2}, 10 \mathrm{~mol} \% \mathrm{Cy}_{3} \mathrm{P}$, in a mixture of toluene and DMF at $250{ }^{\circ} \mathrm{C}$ for $15 \mathrm{~min}$ in a microwave reactor led to 5-arylated triazoles in good to high yields (Scheme 4)[14].

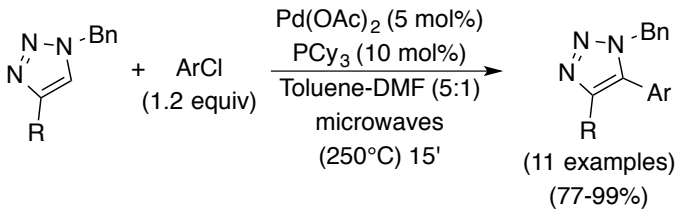

$$
\begin{aligned}
& \mathrm{R}=\mathrm{Ph}, n-\mathrm{C}_{6} \mathrm{H}_{13} \\
& \mathrm{Ar}=2-\mathrm{MeC}_{6} \mathrm{H}_{4}, 4-\mathrm{EtOOCC}_{6} \mathrm{H}_{4}, 4-\mathrm{MeOCC}_{6} \mathrm{H}_{4}, 4-\mathrm{AcOCH}_{2} \mathrm{C}_{6} \mathrm{H}_{4} \text {, } \\
& \mathrm{C}_{6} \mathrm{H}_{5}, 2-\left(\mathrm{C}_{6} \mathrm{H}_{5}\right) \mathrm{C}_{6} \mathrm{H}_{4}, 2,6-(\mathrm{Me})_{2} \mathrm{C}_{6} \mathrm{H}_{3}, \mathrm{HOCH}_{2} \mathrm{C}_{6} \mathrm{H}_{4}
\end{aligned}
$$

Scheme 4. Microwave-assisted synthesis of 5-arylated 1,2,4-triazoles from aryl chlorides Ester and hydroxy groups were found to be compatible, among a variety of functional groups. It should be noted, however, that despite the high temperatures easily attained in a microwave apparatus, this approach was not generally applied to direct arylations of heteroarenes, probably due to scale-up issues and to the elevated costs of microwave reactors, and traditional oil baths are still widely used. As an example of this last statement, one year later a new generally applicable, palladium-catalyzed direct arylation of 1,2,3-triazoles with aryl chlorides was accomplished through conventional heating at $105-120{ }^{\circ} \mathrm{C}[15]$. Both $N$-aryl and $N$-alkyl substituted 1,4-disubstituted 1,2,3-triazoles were converted to the fully substituted heteroarenes. The catalyst system displayed an elevated tolerance towards important functional groups such as ester and carbonyl groups.

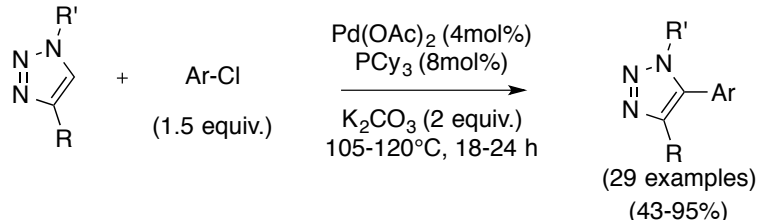

$$
\begin{aligned}
& \mathrm{R}=\mathrm{Ph}, 4-\mathrm{MeOC}_{6} \mathrm{H}_{4}, n-\mathrm{C}_{5} \mathrm{H}_{11}, n-\mathrm{Bu}, \mathrm{CH}_{2} \mathrm{OTMS} \\
& \mathrm{R}^{\prime}=\mathrm{Bn}, \text { PMP-Oct, Ph, 3-MeC } 6 \mathrm{H}_{4}, 2-\mathrm{MeC}_{6} \mathrm{H}_{4}, 2-\mathrm{MeOC}_{6} \mathrm{H}_{4} \\
& \mathrm{Ar}=4-\mathrm{MeC}_{6} \mathrm{H}_{4}, 2-\mathrm{MeOC}_{6} \mathrm{H}_{4}, 4-\mathrm{EtOOCC}_{6} \mathrm{H}_{4}, 4-\mathrm{Me}(\mathrm{O}) \mathrm{CC}_{6} \mathrm{H}_{4}, 4-\mathrm{NCC}_{6} \mathrm{H}_{4} \text {, 3-Py, 2-Py } \\
& \text { 3- } \mathrm{MeOOCC}_{6} \mathrm{H}_{4}, 3-\mathrm{MeOC}_{6} \mathrm{H}_{4}, 4-t-\mathrm{Bu}(\mathrm{O}) \mathrm{CC}_{6} \mathrm{H}_{4}, 3,5-(\mathrm{OMe})_{2} \mathrm{C}_{6} \mathrm{H}_{3}
\end{aligned}
$$

Scheme 5. Synthesis of fully substituted 1,2,3-triazoles through direct arylation under conventional heating

In 2007, Chiong and Daugulis developed what may be considered the first general method for the direct arylation of heteroarenes with aryl chlorides[16]. This procedure made use of a combination of $\mathrm{Pd}(\mathrm{OAc})_{2}$ and $\mathrm{BuAd}_{2} \mathrm{P}$ as palladium ligand, $\mathrm{K}_{3} \mathrm{PO}_{4}$ as the base, in NMP (Scheme 6). 


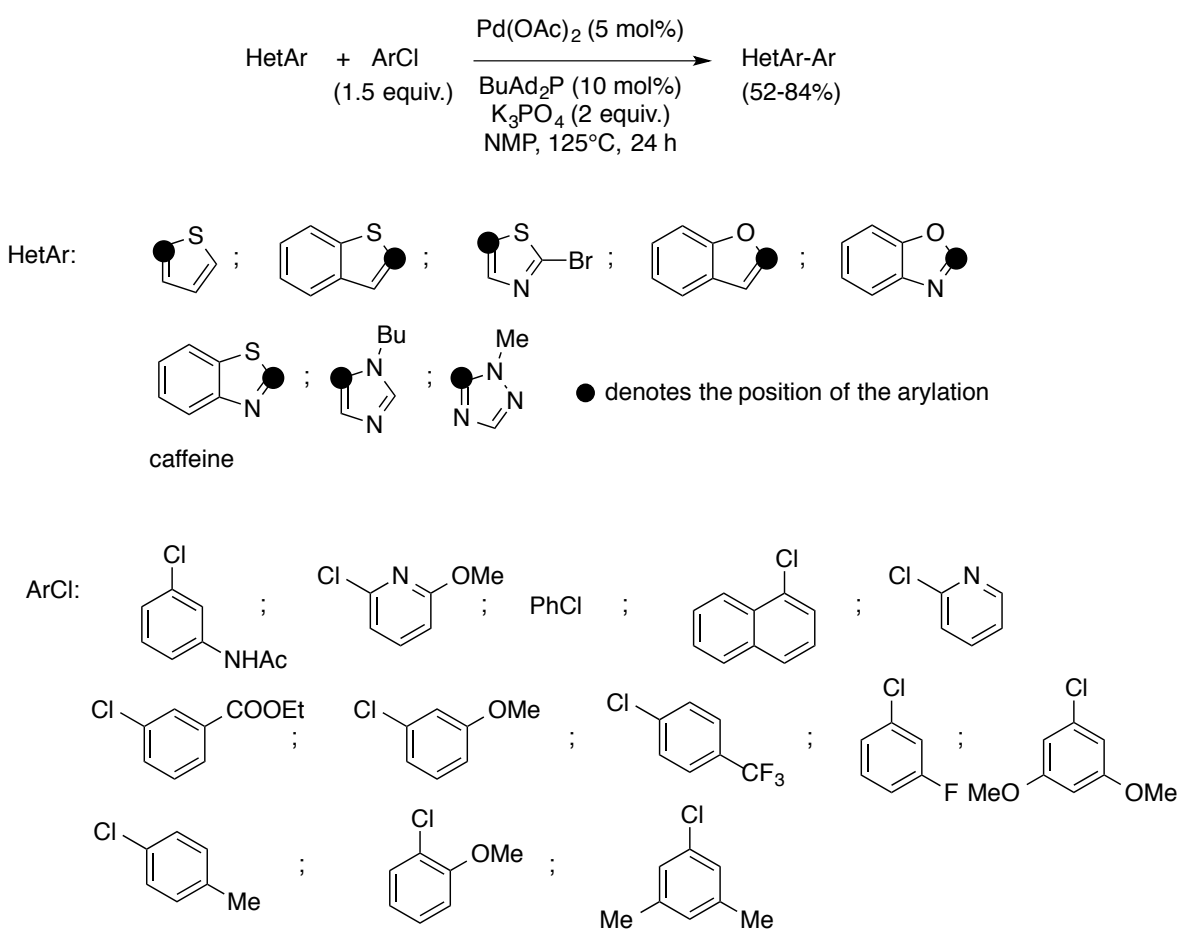

Scheme 6. General method for the Pd-catalyzed direct arylation of heteroarenes with aryl chlorides Both electron-rich and electron-poor aryl chlorides can be used but, as expected, electron-poor chlorides are more reactive due to the easier oxidative addition with $\operatorname{Pd}(0)$ active catalyst. Some steric hindrance is tolerated in both the coupling partners. As regards the mechanism, the authors suggested that a classical electrophilic aromatic substitution could be the most plausible mechanistic pathway for this specific reaction.

The use of a particular ferrocenyl triphosphine in the direct arylation of heteroarenes with aryl chlorides that allowed low palladium loadings was described by Doucet and co-workers[17]. The couplings were carried out in DMA at $150{ }^{\circ} \mathrm{C}$ for $16 \mathrm{~h}$, employing 2.0 equiv of $\mathrm{AcOK}$ as the base (Scheme 7). Notably, the authors found that carrying out the reactions under Jeffery's conditions, i.e. in the presence of the ammonium salt $n \mathrm{Bu}_{4} \mathrm{NBr}$, resulted beneficial for the coupling, and that ligand-free conditions were ineffective.

Electron-rich, electron-poor and polysubstituted furans, thiophenes, pyrroles, and thiazoles were arylated by using catalyst loadings of $0.5 \mathrm{~mol} \%$. This protocol tolerates important and useful functionalities such as formyl, nitro, cyano, keto, and ester groups, in ortho, meta, and para positions. 


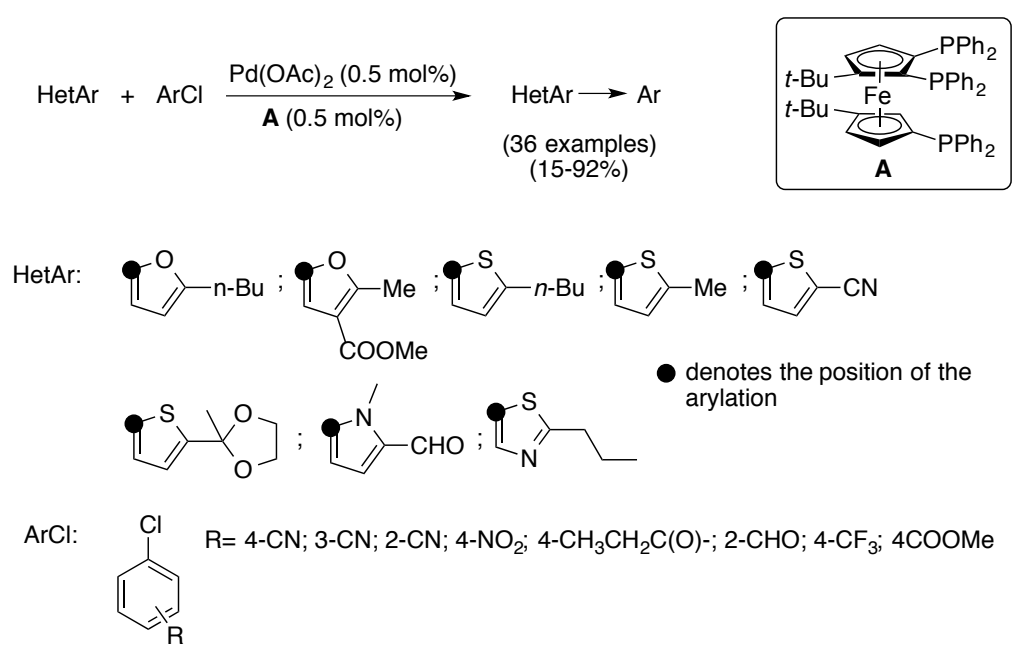

Scheme 7. Low palladium-loading procedure for the direct aylation of azoles with aryl chlorides In 2010 chemists at Merck developed general conditions fot the highly regioselective direct C2 or C5 arylation of oxazoles with aryl chlorides[18]. This method represented the first general method for the $\mathrm{C} 5$ arylation of oxazole, which is the relevant structural core in many natural products and pharmaceuticals. The regioselectivity towards C5 or C2 arylation was obtained through a careful selection of palladium ligands and solvents. Two sets of experimental conditions allowed the reaction to follow preferentially two competitive distinct pathways: a CMD transition state which led to C5 arylation, or a deprotonative ring-opening ring-closure sequence, that gave the $\mathrm{C} 2$ arylated oxazoles (Scheme 8).

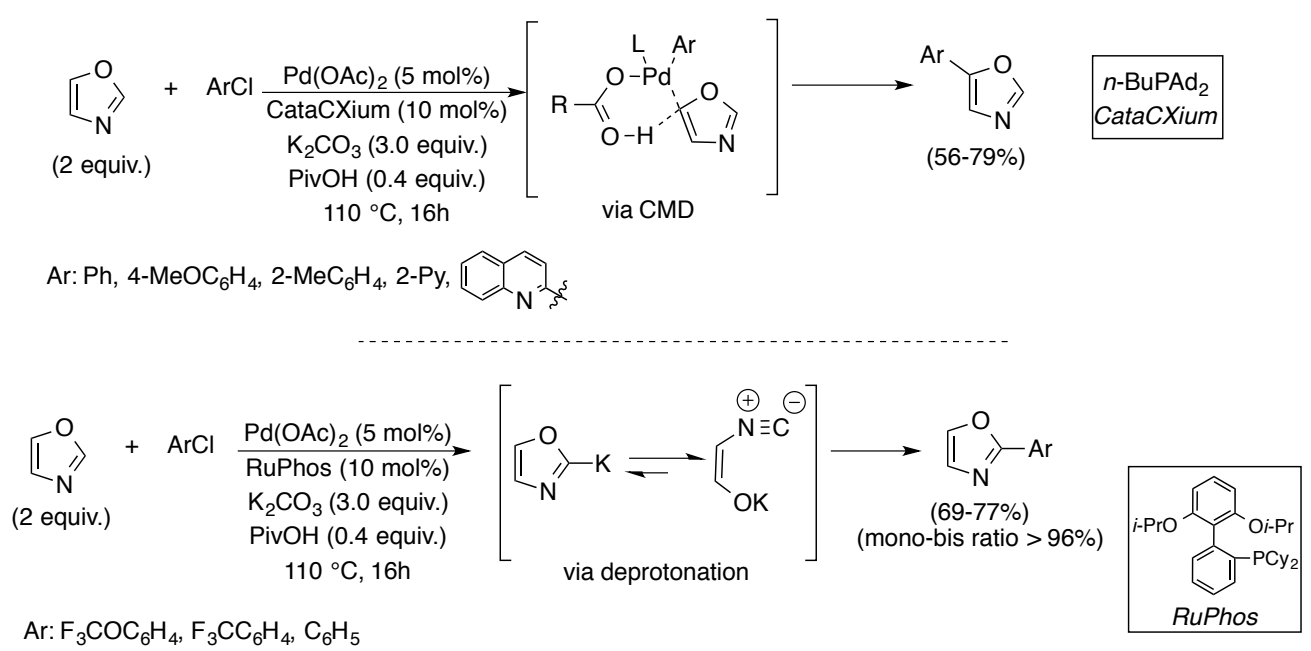

Scheme 8. Regioselective $\mathrm{C} 5$ or $\mathrm{C} 2$ arylation of oxazoles with aryl chlorides

2-Methylthiophene, 2-(4-methoxyphenyl)thiophene, 3-n-hexylthiophene, and benzothiophene were successfully reacted with typical electron-rich and electronpoor aryl chlorides using $\mathrm{LiO} t \mathrm{Bu}$ as the base (Scheme 9)[19]. The combination of a strong base with the basic $\mathrm{P} t \mathrm{Bu}_{3}$ ligand allowed the coupling to proceed 
smoothly, giving rise to the required arylated heheroarenes in $58-92 \%$ isolated yields.

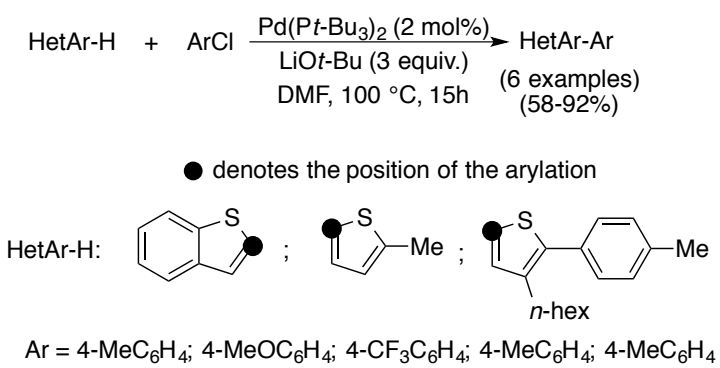

Scheme 9. Direct arylation of thiophene derivatives with $\mathrm{LiO} t \mathrm{Bu}$

The electron-rich NHC-Pd(II) complex B was found to be an efficient precatalyst for the regioselective C5 direct arylation of imidazoles with aryl chlorides (Scheme 10)[20].

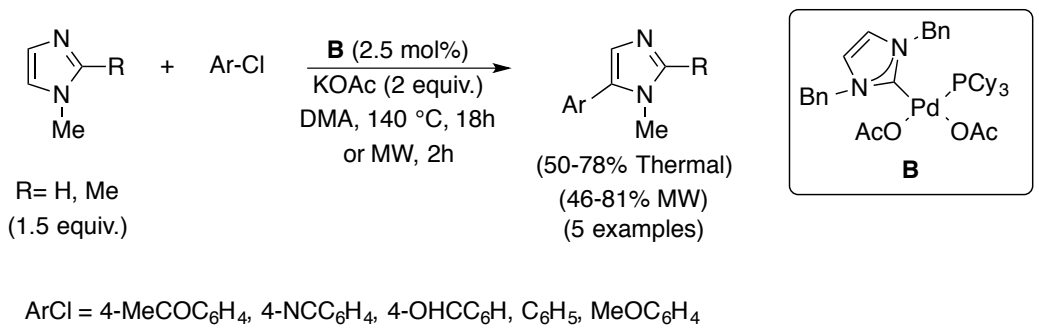

Scheme 10. NHC-Pd(II) promoted direct C5 arylation of imidazoles with aryl chlorides

The authors found that microwave irradiation effectively promoted the coupling, obtaining good yields in only two hours. When 1-methyl- $1 H$-imidazole was used as the coupling partner, low amounts (less than 10\%) of the corresponding 2-aryl or 2,5-diaryl substituted imidazoles were also isolated. The authors, taking into account the higher reactivity of the more nucleophilic 1,2-dimethylimidazole in comparison with 1-methylimidazole, suggested that the probable rate-determining $\mathrm{C}-\mathrm{H}$ cleavage should occur via an electrophilic aromatic substitution pathway. In 2011 Daugulis and co-workers found that $N$-substituted indoles, $N$ methylpyrroles and furans were able to react with a variety of aryl chlorides employing $\mathrm{Pd}(\mathrm{OAc})_{2}$ and 2-(dicyclohexylphosphino)biphenyl as ligand[21]. Arylated heteroaromatics were obtained in moderate to good yields, but the authors noticed that a careful optimization of base, ligand, and solvent was required for each heteroaromatic in order to achieve the best results. As regards indoles, both activated and deactivated aryl chlorides were reactive when used in a elevated molar excess (5.0 equiv) (Scheme 11), and a variety of 2- or 3substituted $N$-methylindoles were efficiently arylated at their 3 or 2 free position. 


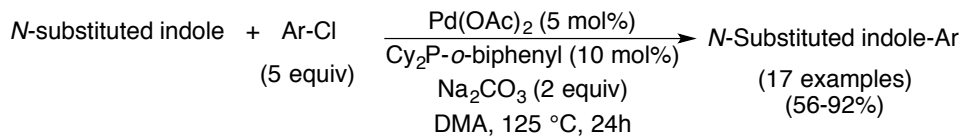

$N$-substituted indoles:

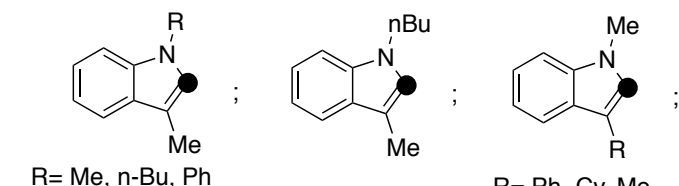

$$
\mathrm{R}=\mathrm{Ph}, \mathrm{Cy}, \mathrm{Me}
$$

- denotes the position of the arylation

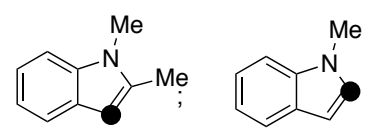

ArCl:<smiles>COc1cccc(Cl)c1</smiles><smiles>P</smiles><smiles>Cc1cccc(Cl)c1</smiles><smiles>Cc1cc(C)cc(Cl)c1</smiles>
$\mathrm{R}=\mathrm{H}, \mathrm{OMe}, \mathrm{F}$<smiles>Cc1ccc(Cl)cc1C</smiles><smiles>CCOC(=O)c1ccc(Cl)cc1</smiles>

Scheme 11. Direct arylation of $N$-substituted indoles with aryl chlorides

However, the authors evidenced the fact that unprotected indoles afforded mostly $\mathrm{N}$-arylated analogues under the developed reaction conditions. Moreover, siliconcontaining protective groups were removed, and indoles bearing electronwithdrawing groups on nitrogen were decomposed or gave low yields. When $N$-methylpyrroles were reacted with aryl chlorides, it was found that a severe molar excess of azole (5.0 equiv) was required to avoid diarylation, but electron-poor and electron-rich chlorides were found to be equally reactive. The optimized conditions for $N$-methylpyrroles required $\mathrm{K}_{3} \mathrm{PO}_{4}$ as the base, and NMP as the solvent (Scheme 12).

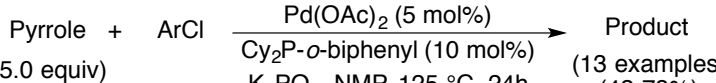

$$
\begin{aligned}
& \begin{array}{lc}
\text { (5.0 equiv) } \quad \mathrm{K}_{3} \mathrm{PO}_{4}, \mathrm{NMP}, 125^{\circ} \mathrm{C}, 24 \mathrm{~h} & (13 \text { examples) } \\
& (42-78 \%)
\end{array}
\end{aligned}
$$

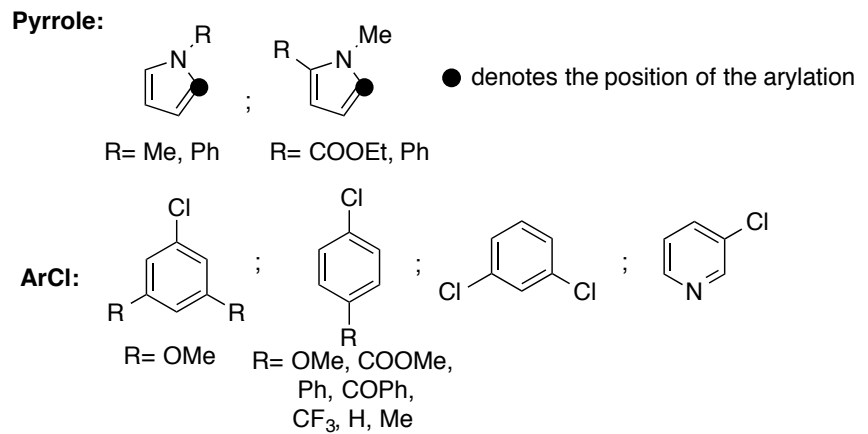

Scheme 12. Direct arylation of $N$-methylpyrroles with aryl chlorides

Several equivalents of furan were necessary to avoid diarylation, while for monosusbtituted furans an excess of aryl chloride was required (Scheme 13) 


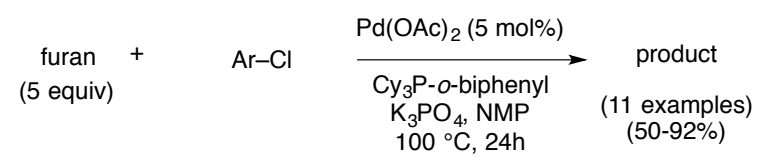

Furan:

R= R, COOEt, Me

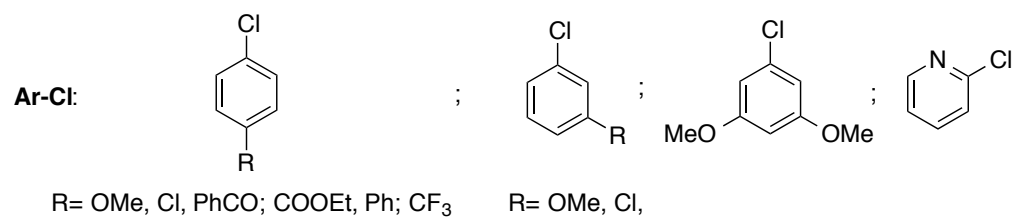

Scheme 13. Direct arylation of furans

In an effort to prepare new organic fluorophores containing the indolizine core, in 2012 Yuo, Lau and co-workers developed a straightforward method for the direct arylation not only of a variety of substituted indolizines, but also amenable to the arylation of several electron-rich as well as electron-deficient heteroarens. In fact, xanthines such as caffeine, thephlyline and theobromine, purines, imidazoles, thiazoles oxazoles, 1,2,3-triazoles, and $N$-heteroarene $N$-oxides, were efficiently arylated using $p$-chlorotoluene as a model electrophilic partner (Scheme 14)[22]. 


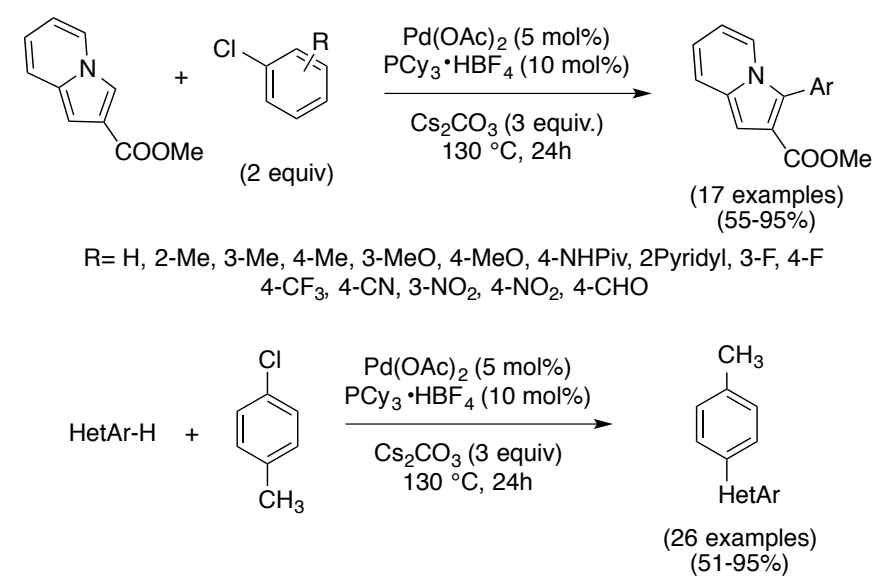

HetAr-H:
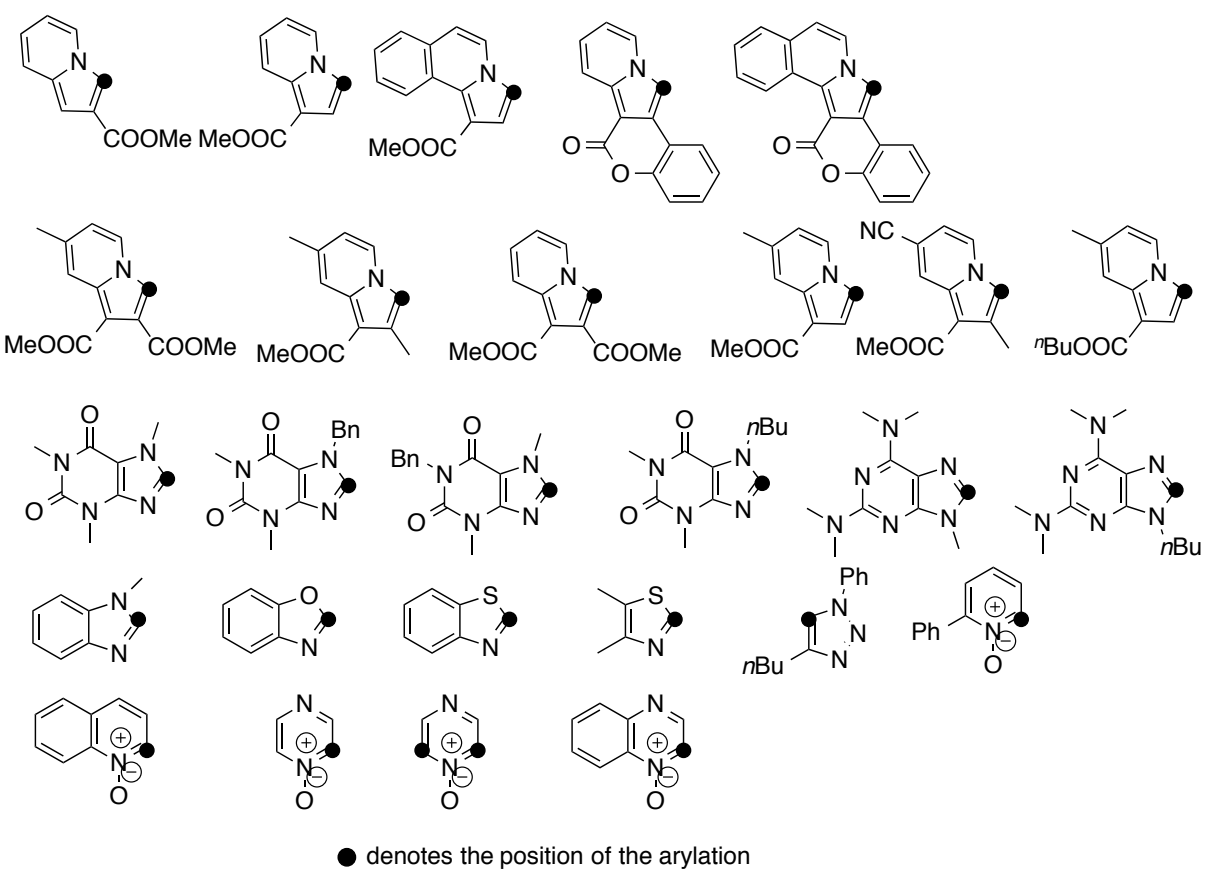

Scheme 14. Direct arylation of indolizines and other heteroarenes with aryl chlorides

Once again, the key of the success of this arylation procedure is represented by a careful optimization of the reaction system, including base, palladium ligand, and solvent.

In the same year, Gosh and Lee observed that all the previously published methods involving aryl chlorides suffered from low yields when hindered chlorides were used. Hence, they developed an interesting protocol for the direct arylation of heteroarenes with sterically hindered aryl chlorides where a $\mathrm{Pd}(\mathrm{II})$ complex $\mathbf{B}$ bearing a functionalized $\mathrm{NHC}$ and a $\mathrm{PCy}_{3}$ had a key role[23]. In the presence of $2.0 \mathrm{~mol} \% \mathrm{~B}, 30 \mathrm{~mol} \% \mathrm{PivOH}, 1.5$ equiv $\mathrm{K}_{2} \mathrm{CO}_{3}$ in DMA for $12 \mathrm{~h}$ at $110{ }^{\circ} \mathrm{C}, 2$-substituted furans, thiophenes and $N$-methylpyrroles were successfully coupled with a variety of aryl chlorides, including several sterically encumbered ones (Scheme 15). 

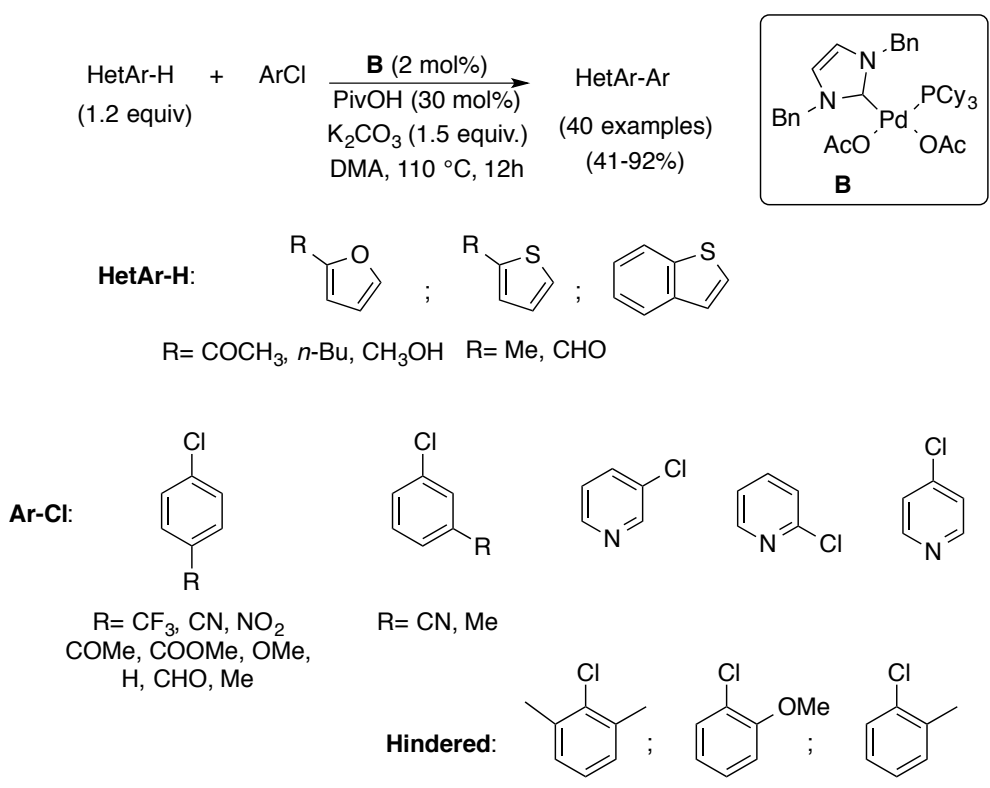

Scheme 15. Direct arylation of heteroarenes with sterically demanding aryl chlorides

Interestingly, free aliphatic hydroxy, formyl, and keto functional groups were well tolerated by this catalyst systems. Under this protocol, a twofold $\mathrm{C}-\mathrm{H}$ bond arylation was also successfully accomplished (Scheme 16).

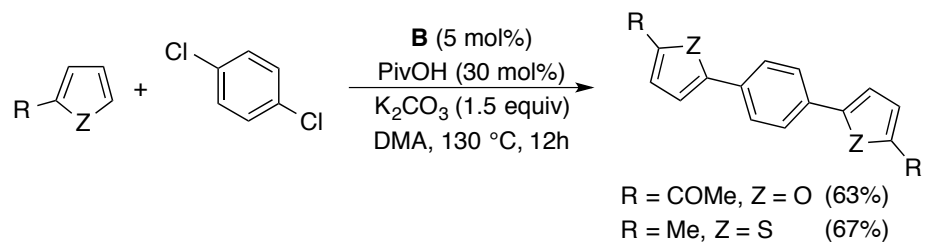

Scheme 16. Double direct arylation with aryl chlorides

Through competitive and kinetic isotopic experiments the authors concluded that a concerted metalation-deprotonation (CMD) pathway rather than an electrophilic aromatic substitution or radical processes should be involved in the ratedetermining $\mathrm{C}-\mathrm{H}$ cleavage step.

Finally, in 2014, Sheo and co-workers were able to achieve a clean direct arylation of oxazoles and benzoxazoles with aryl chlorides using a well defined palladium(II) complex $\mathbf{C}$ bearing an NHC and an unusual $\mathrm{N}$-methylimidazole as ancillary ligand[24]. This procedure allowed the preparation of the corresponding 2-arylated (benzo)oxazoles in modest to good yields. 


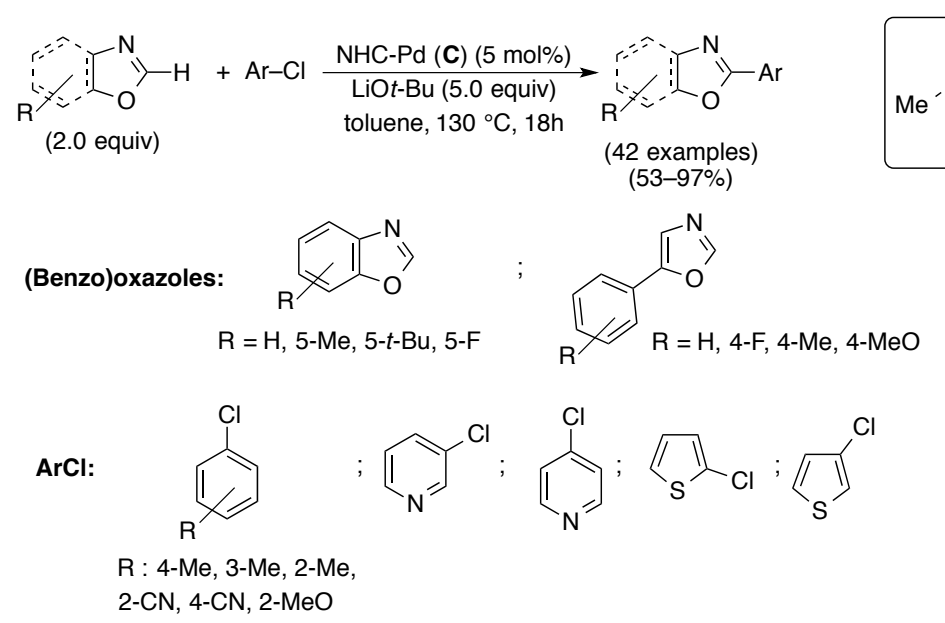

Scheme 17. Direct arylation of heteroarenes promoted by a mixed NHC- $N$-methylimidazole Pd(II) complex

The optimal reaction conditions were selected through the usual careful screening of bases and solvents, using benzoxazole and chlorobenzene as model coupling partners. It is intriguing to observe the fact that the precatalyst bears an imidazole as ligand, which at least in principle may be reactive under the proposed reaction conditions at one of its $\mathrm{C}-\mathrm{H}$ bonds. It may then be argued, from the reported results, that coordination of azoles to palladium may significantly influence the outcome of direct arylations. The beneficial effect of using an excess of azoles may hence be related not only to an enhancement of the selectivity towards monoarylated products (as it is generally stated), but also to the formation of more active catalysts. On the other hand, the coordination of azoles to palladium catalysts may also lead to a deleterious effect, as it may be hypothesized in the case of direct arylations involving $\mathrm{NH}$-free imidazole, which is extraordinary unreactive with aryl halide in the presence of palladium catalysts and bases (while it may be arylated at $\mathrm{C} 2$ under ligandless and base-free conditions using a mixed Pd-Cu co-catalysis[25]).

\section{Blocking/activating removable functional groups}

\section{Functional group on nitrogen}

While $\mathrm{N}$-substituted azoles are generally reactive in direct arylations, the use of $\mathrm{N}$ unprotected derivatives has been found to be difficult when not impossible, probably due to palladium poisoning. Till today, for example, as stated in the previous chapter, free $\mathrm{NH}$-imidazole is unable to react with aryl halides in the presence of a palladium catalyst alone. Hence, various protective groups have 
been used to allow the recovery, after deprotection, of arylated azoles bearing free nitrogen-hydrogen bonds. The role of these groups, as it will be discussed in the next paragraphs, frequently is not limited to a simple protection of N-H bonds of heteroarenes, but they may have a significant effect on the reactivity of the heteroarene and on the regioselectivity of the coupling.

The use of deprotonated azoles in direct arylations may represent the simplest "protection" of the NH moiety of azoles. The first use of an azole anion in direct arylation was reported by Sadighi and co-workers in 2004[26]. They reported that using a palladium precatalyst and sterically demanding phosphinobiphenyl ligands, pyrrolylzinc chlorides may be successfully coupled with a wide range of aryl bromides and chlorides, including highly sterically encumbered ones. The pyrrolylzinc anions were generated in situ from pirrolylsodium (from pyrrole and $\mathrm{NaH}$ ) and zinc dichloride (Scheme 18).

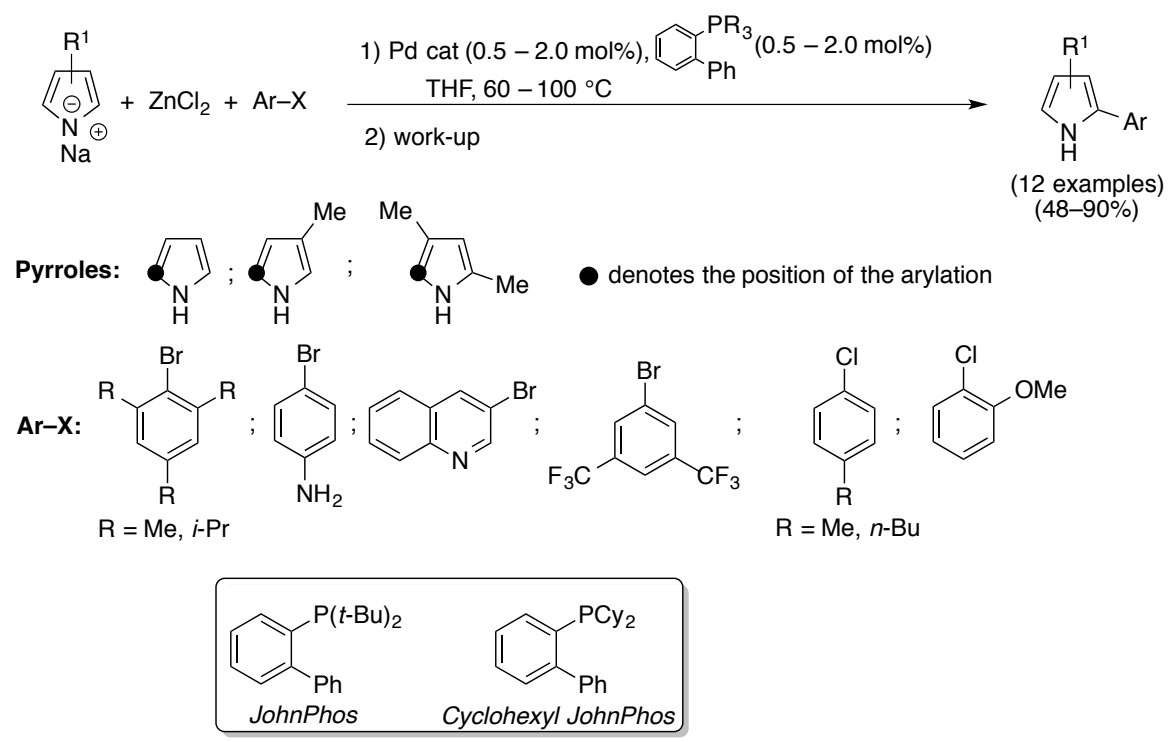

Scheme 18. Direct arylation of pyrrolylzinc chlorides with aryl halides

A combination of $\mathrm{Pd}(\mathrm{OAc})_{2} / \mathrm{JohnPhos}$ and 1.6 equiv of anion was generally used, while in cases of more sterically demanding substrates the use of $\operatorname{Pd}_{2}(\mathrm{dba})_{3}$ in combination with Cyclohexyl JohnPhos resulted more effective.

Fagnou and co-workers disclosed, in a series of papers dated back to 2005, the synthetic potential of azine and azole $N$-oxides in ortho direct arylations[27]. The results of these studies showed that for azine $N$-oxides the regioisomeric distribution is governed by the nature of the azine, and may be influenced by the choice of the palladium ligand (Scheme 19). 

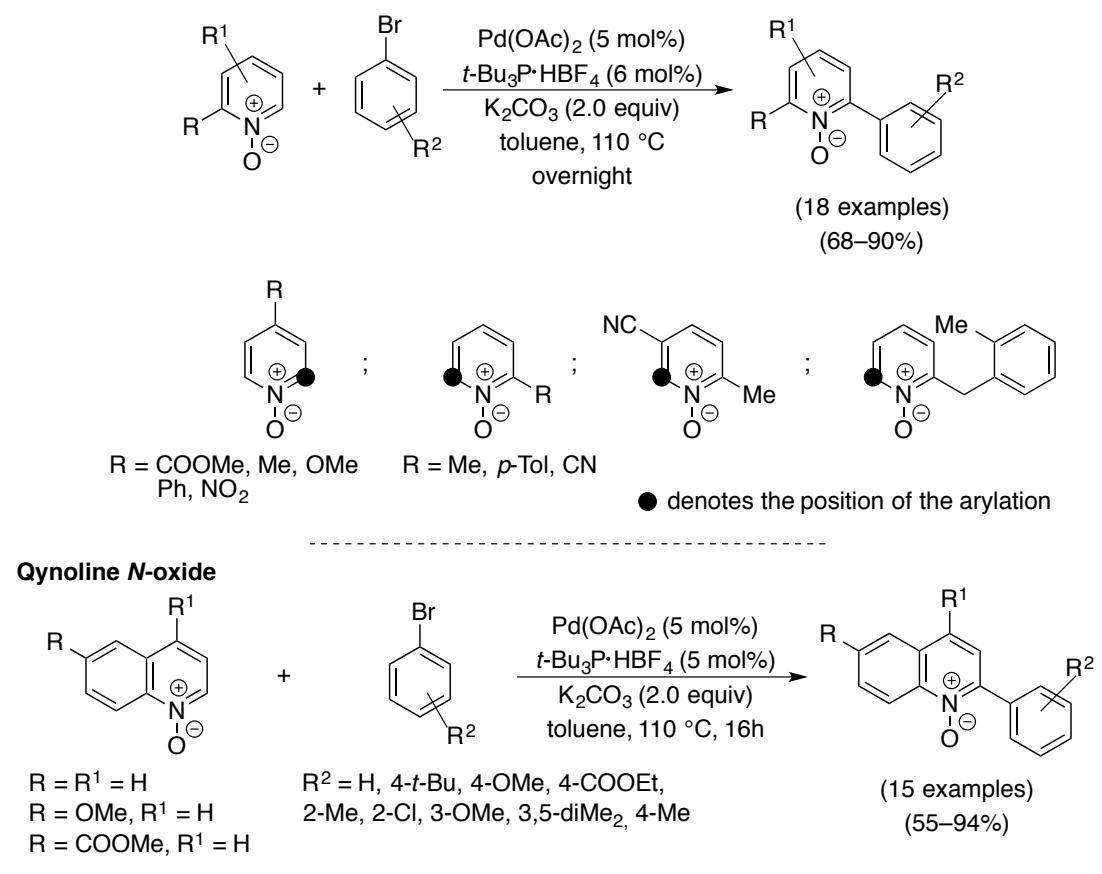

Isoqynoline $\boldsymbol{N}$-oxide: selectivity

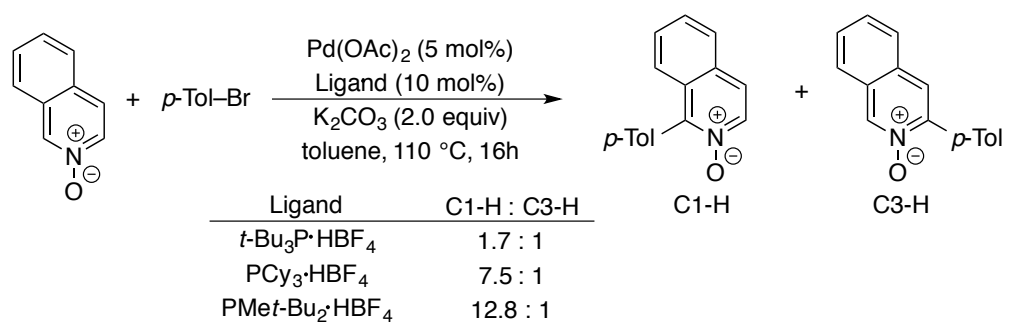

Scheme 19. Direct arylation of azine $N$-oxides with aryl halides

For what concerns azole $\mathrm{N}$-oxides, preferential reaction occured at $\mathrm{C} 2$ under very mild reaction conditions. Subsequent arylation involved $\mathrm{C} 5-\mathrm{H}$, followed by $\mathrm{C} 4-\mathrm{H}$. As an example of the importance of the optimized protocols for the sequential C2$>\mathrm{C} 5->\mathrm{C} 4$ arylations for thiazole $\mathrm{N}$-oxides, and $\mathrm{C} 2->\mathrm{C} 4$ for imidazole $\mathrm{N}$-oxides, the synthesis of a Tie 2 Tyrosine kinase inhibitor was successfully achieved (Scheme 20)[27b]. 


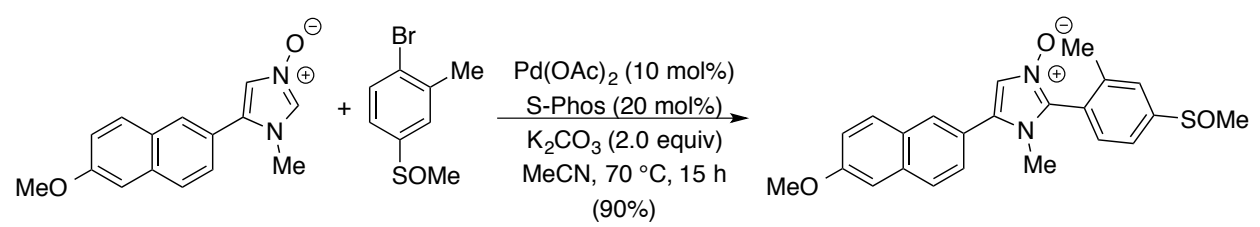
$(90 \%)$
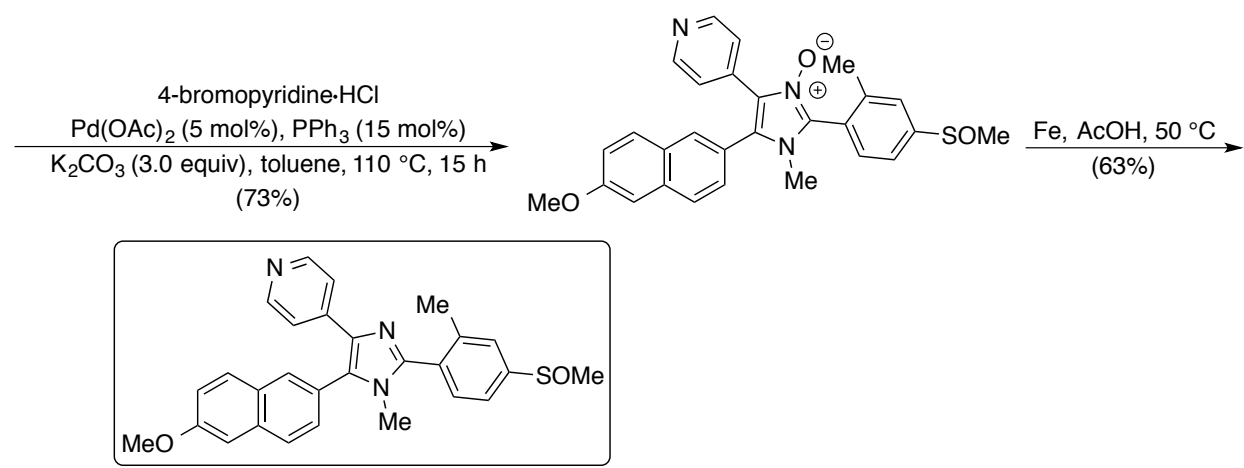

Scheme 20. Synthesis of Tie 2 Tyrosine kinase inhibitor by sequental direct arylations of 1,3-azole $N$-oxides with aryl halides

Note that at the end of the synthetic sequence, the $N$-oxide function was easily removed by reduction with $\mathrm{Fe}$ in $\mathrm{AcOH}$.

The regioselective direct arylation of 6- and 7-azaindole cores could be achieved using $\mathrm{N}$-oxide activation strategy, which led the functionalization of $\mathrm{C}-\mathrm{H}$ bonds usually unreactive on the parent heteroarenes (Scheme 21) [27c].

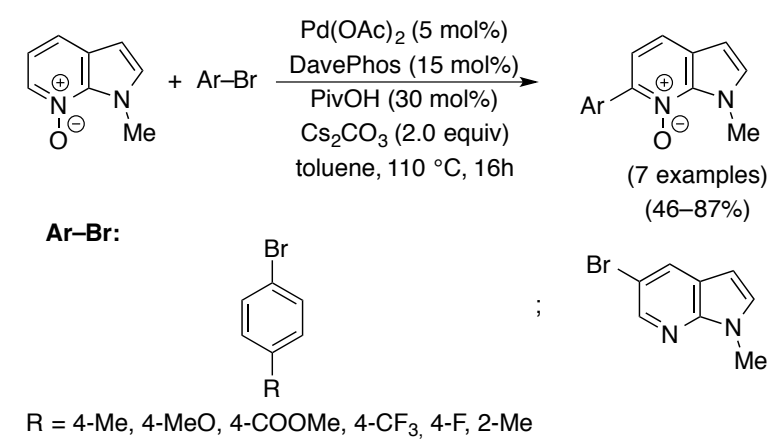

Scheme 21. Direct arylation of 6- and 7-azaindole $N$-oxides

The synthetic importance of hetarene $N$-oxides, disclosed by Fagnou's group, has received increasing attention due to the possibility of activating $\mathrm{C}-\mathrm{H}$ bonds usually unreactive, and to the different methods available for the subsequent deoxygenation of the arylated $N$-oxides. Their reactivity has been widely explored, and at present not only the arylation is feasible on a wide range of azine and azole $N$-oxides, but also alkenylation, alkylation, acyloxylation, amination and sulfonylation involving these interesting synthetic intermediates may be easily carried out[28].

In a series of papers Sames and co-workers described effective protocols for performing multiple arylations of pyrazoles[29], imidazoles[30] and 1,2,4- 
triazoles[31]. The key feature of these methods is the use of the transposition of the SEM protective group of nitrogen atoms of these azoles, allowing the functionalization of the otherwise unreactive $\mathrm{C} 3-\mathrm{H}$ bond of pyrazoles and 1,2,4triazoles, and of C4-H bond of imidazoles (Scheme 22).

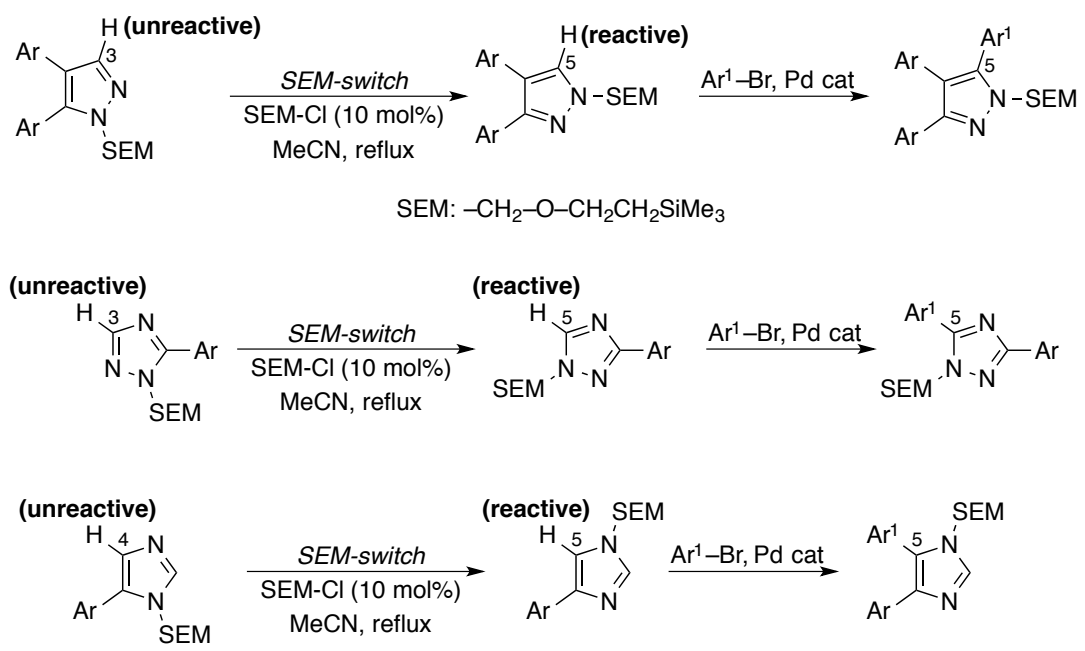

Scheme 22. Direct arylation of $N$-SEM protected azoles through switch of the protective group.

\section{Functional group on carbon}

In contrast with direct arylations involving arenes, the presence of heteroatoms in heteroarenes often introduces significant differences in the reactivity of the various $\mathrm{C}-\mathrm{H}$ bonds, allowing at least in principle the attainment of good regioselectivities. However, classical direct arylation protocols carried out on simple heteroarenes generally involve only one of the different $\mathrm{C}-\mathrm{H}$ bonds present on the heteroaromatic core. Depending on the active mechanistic pathway, usually only the most nucleophilic carbon atom or the most acidic $\mathrm{C}-\mathrm{H}$ bond is involved in the coupling with aryl halides, while the other positions remain unreactive. Hence, when these last positions have to be arylated due to synthetic needs, a common strategy to overcome this regioselectivity issue is represented by the employment of specific functional groups that are able to block the most reactive position, allowing the arylation to involve otherwise unreactive $\mathrm{C}-\mathrm{H}$ bonds. Silylated and carboxyalkyl functionalities, or a chlorine atom, are among the most common activating/blocking groups due to their stability under the arylation reaction conditions and to the methods available for their removal.

As the desilylation of heteroaromatics is relatively easy, the presence of silyl substituents might be useful to block reactive positions enabling, at the same time, the functionalization of unreactive $\mathrm{C}-\mathrm{H}$ bonds. This approach was demonstrated 
by the arylation of 2-(trimethylsilyl)-5-methylthiophene at its $\mathrm{C} 4$ position (Scheme 23)[32].

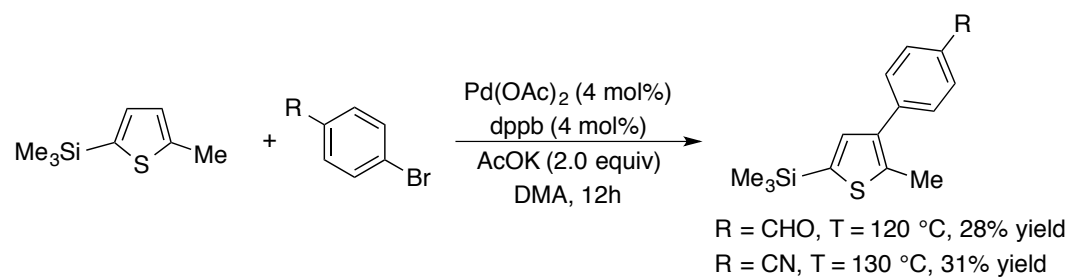

Scheme 23. Direct arylation of a 2-TMS protected thiophene.

Searching for direct arylation routes to bioactive polyazoles, Greaney and coworkers synthesized C2 TIPS-protected 4-iodooxazole, which was then employed in a short synthesis of the trisoxazole core of the antifungal Ulapualide A (Scheme 24)[33].

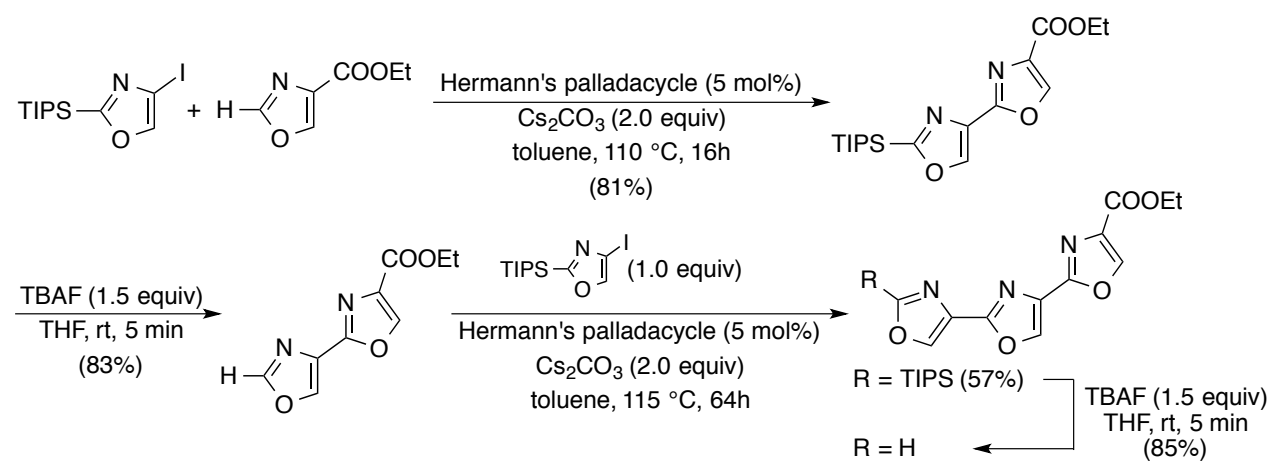

Scheme 24. Direct arylation involving a C2 TIPS-protected oxazole towards the synthesis of the trisoxazole core of Ulapualide A.

Alternatively to the two step sequential direct arylation-desilylation depicted in Scheme 24 , the deprotection of the bisoxazole may be performed directly on the crude reaction mixture obtained by direct $\mathrm{C} 2$ arylation of 4-carboxyethyloxazole, by diluting it with THF and reacting with TBAF (1.0 equiv) for $5 \mathrm{~min}$ at room temperature. In this case, the combined yield over the two steps was $71 \%$. Chloride atom may be used to improve and/or to induce regioselectivity, and may be easily removed at the end of the synthetic sequence. For example, while the direct arylation of 3-hexylthiophene with 4-bromonitrobenzene gave two regioisomeric derivatives in a 1.3:1 molar ratio, blocking one of the two $\alpha$ position on thiophene allowed a clean arylation at the remaining free $\mathrm{C}-\mathrm{H}$ bond (Scheme 25)[34]. 

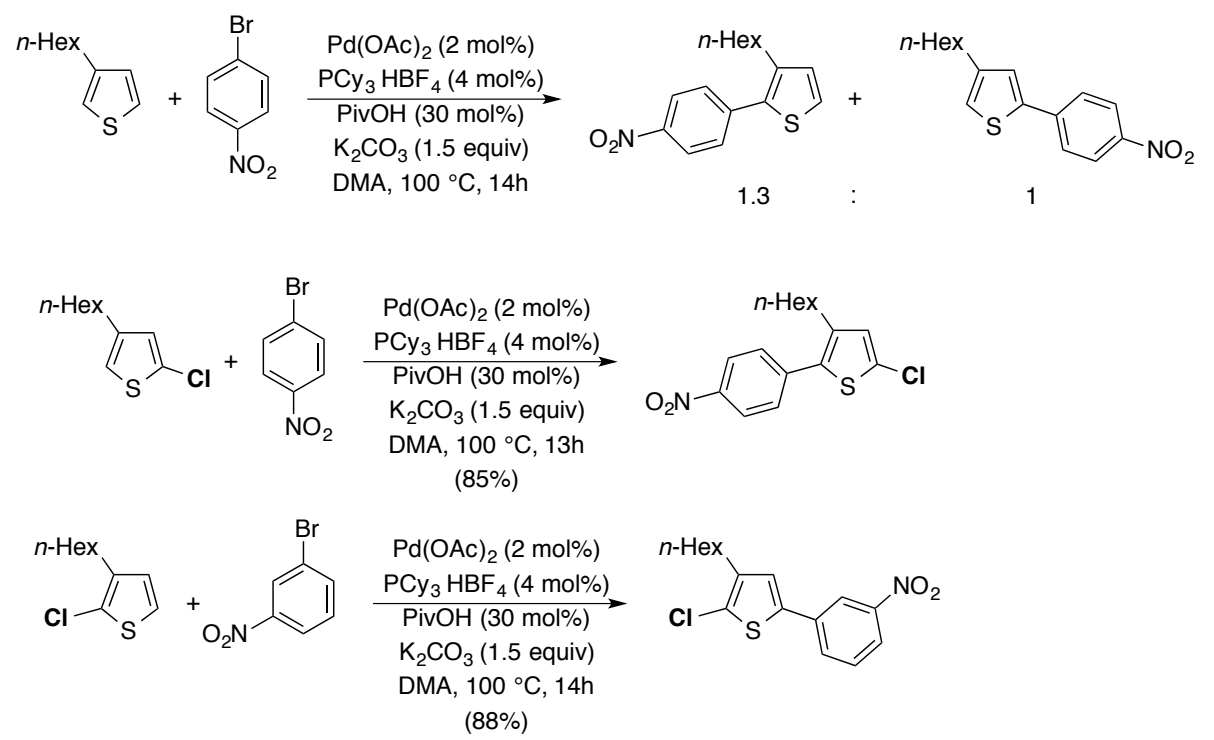

Scheme 25. Regioselective arylation of chloro-substituted thiophenes

The deprotective reduction was easily carried out with $10 \mathrm{~mol} \% \mathrm{Pd} / \mathrm{C}, \mathrm{H}_{2}(1 \mathrm{~atm})$, $\mathrm{Et}_{3} \mathrm{~N}$ (1.2 equiv) in $\mathrm{MeOH}$ at room temperature for $5 \mathrm{~h}$, giving rise to the required dehalogenated products in yields higher than $85 \%$.

In a similar way, other chlorinated azoles were efficiently arylated also at positions generally not reactive when the same reaction conditions were applied to the direct arylation of chlorine-free analogues (Figure 1)[34].

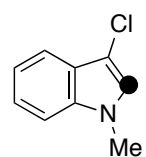

(on 1-methylindole, C3/C2 mixture)

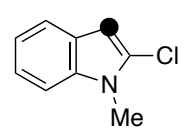

denotes the position of the arylation

Figure 1. Regioselectivity of direct arylations involving chlorine-substituted azoles

A carbomethoxy group, which could be easily removed by base-promoted decarboxylation, was used by Doucet and co-workers to block position 2 on 3amminothiophene, allowing for the first time the direct arylation of an heteroarene bearing a free $\mathrm{NH}_{2}$ group (Scheme 26)[35].<smiles>COC(=O)c1scc(OC)c1N</smiles>

Ar-Br:

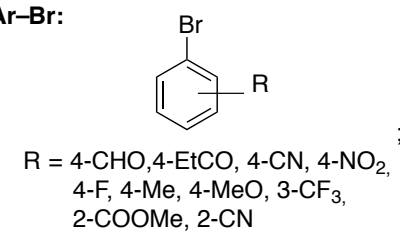

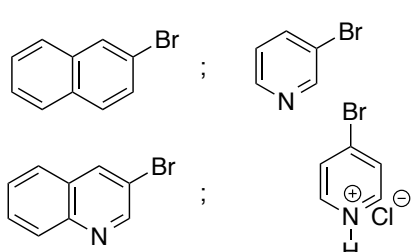

$\mathrm{H}$

Scheme 26. Regioselective C5 arylation of 3-ammino-2-carbomethoxythiophene 
Employing $\mathrm{KOH}$ along with $\mathrm{KOAc}$, only the 2-arylated derivatives were observed through decarboxylation-arylation. The authors argued that in these cases the amino group may play a role in coordinating palladium species and directing the electrophilic palladation at $\mathrm{C} 2$. For example, the reaction of 3-ammino-2 carboxymethyl-4-methylthiophene with 4-bromo toluene gave the corresponding 2-arylated thiophene in 64\% isolated yield (eq. 1).

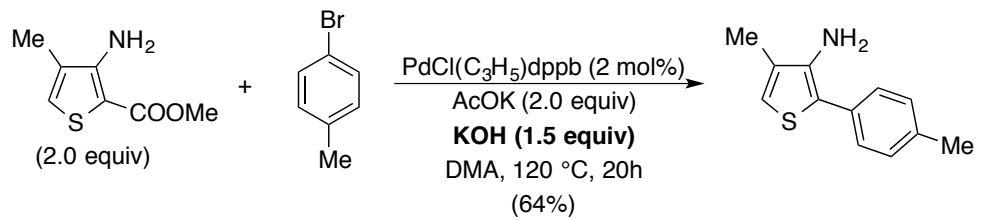

\section{Heterogeneous palladium catalyst systems}

With the aim to develop more sustainable direct C-H arylations, the use of heterogeneous catalysts is particularly attractive, although the inertness of the C-H bond has rendered this promising implementation rather difficult[36]. However, the use of heterogeneous catalysts gives a number of advantages: (1) easy catalyst recovery, (2) metal recycling or reprocessing, and (3) reduced metal contamination of solvents and products. Some significant examples of the use of heterogeneous palladium systems are summarized below.

A simple heterogeneously palladium-catalyzed procedure for the selective $\mathrm{C} 3$ arylation of indoles was reported by Cusati and Djakovitch in 2008[37]. Using only $1 \mathrm{~mol} \%$ of $\left[\mathrm{Pd}\left(\mathrm{NH}_{3}\right)_{4}\right]^{2+} / \mathrm{NaY}$ as catalyst, $\mathrm{K}_{2} \mathrm{CO}_{3}$ as the base, in dioxane at reflux, indoles substituted or not at their position 2 gave up to $92 \%$ conversion, and up to $85 \%$ isolated yields of the expected 3-arylated indoles. Notably, no conversion was observed for 2-methyl and 2-phenyl indoles when 4-bromotoluene or 4-bromoanisole were used as coupling partners (Scheme 27).

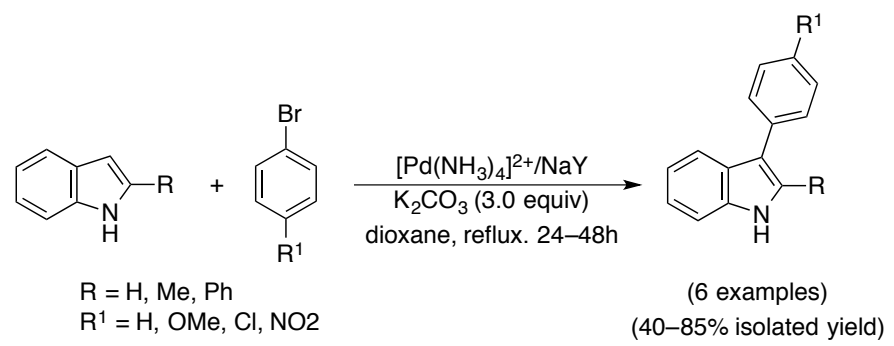

Scheme 27. Direct C3 arylation of indoles promoted by heterogeneous $\left[\mathrm{Pd}\left(\mathrm{NH}_{3}\right)_{4}\right]^{2+} / \mathrm{NaY}$ The authors supposed the cohexistence of two concurrent mechanisms: an electrophilic substitution (ES) vs. an $\mathrm{S}_{\mathrm{N}} \mathrm{Ar}$ mechanism. The ES mechanism, which 
occurs through the coordination of an Ar-Pd-X complex to indole nucleus, is sensible to steric hindrance at position 2 . The second mechanism should occur when activated (i.e. electron-poor) aryl bromides are employed, and mainly with 2-methylindole, which has been demonstrated to be more reactive than indole or 2-phenylindole in such a mechanism. The catalyst was obtained by ion exchange of a NaY zeolite using an aqueous solution of $\left[\mathrm{Pd}\left(\mathrm{NH}_{3}\right)_{4}\right]^{2+} / 2 \mathrm{Cl}^{-}$.

An efficient heterogeneous catalyst system for the $\mathrm{C} 2$ direct arylation of indoles is represented by palladium nanoparticles (Pd NPs) encapsulated in the mesoporous MOF MIL-101(Cr)[38]. The direct arylation required only $0.1 \mathrm{~mol} \% \mathrm{Pd}$, affording the required C2-arylated indoles in good yields (Scheme 28).

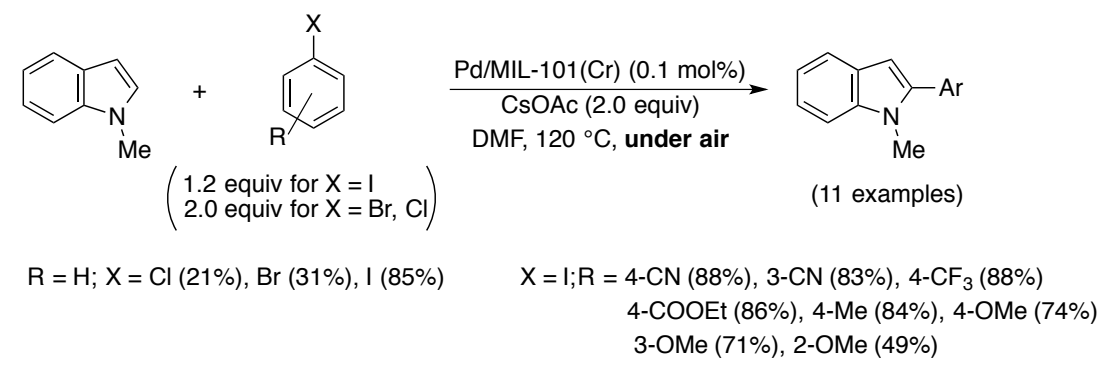

Scheme 28. Direct C2 arylation of indoles promoted by heterogeneous Pd NPs

The heterogeneous catalyst was prepared by simple impregnation with an aqueous solution of $\mathrm{Pd}\left(\mathrm{NO}_{3}\right)_{2}$ of ML-101(Cr) $\left\{\mathrm{Cr}_{3}(\mathrm{~F}, \mathrm{OH})\left(\mathrm{H}_{2} \mathrm{O}\right)_{2} \mathrm{O}\left[\left(\mathrm{O}_{2} \mathrm{C}\right)-\mathrm{C}_{6} \mathrm{H}_{4}-\right.\right.$ $\left.\left(\mathrm{CO}_{2}\right)\right]_{3} \bullet \mathrm{nH}_{2} \mathrm{O}(\mathrm{n} \approx 25)$, MIL: Matérial Institut Lavoisier\}. The Pd leaching resulted very low $(<0.4 \mathrm{ppm})$, and no $\mathrm{Cr}$ was released by the MOF. Two clear advantages of using this catalyst are the fact that the reactions may be carried in the open air, and that the catalyst may be recovered by centrifugation. Moreover, the catalyst still exhibits high reactivity after five runs (a decrease of only $4 \%$ was observed). Pearlman's catalyst $\left(\mathrm{Pd}(\mathrm{OH})_{2} / \mathrm{C}\right)$ was found to catalyze direct arylation reactions of several azoles and 2-formylfuran with aryl bromides (Scheme 29)[39].

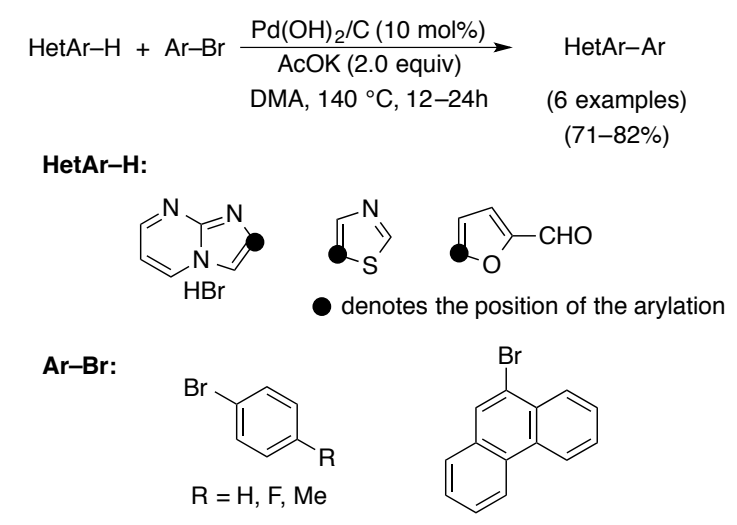

Scheme 29. Direct arylation of heterarenes promoted by Pearlman's catalyst 
Authors proved that, in this case, an homogeneous catalyst is generated under the reaction conditions, and that this species is responsible for the observed catalysis. This may account also for the high catalyst loading required by this method, in contrast with homogeneous catalyst systems $(\leq 5 \mathrm{~mol} \%)$.

The effectiveness of the use of heterogeneous $\mathrm{Pd} / \mathrm{C}$ in direct arylation of heteroarenes has been recently demonstrated by the regioselective polycondensation of thiophenes[40]. Linear $\pi$-conjugated alternating copolymers were obtained with high molecular weight in high yields (Scheme 30).

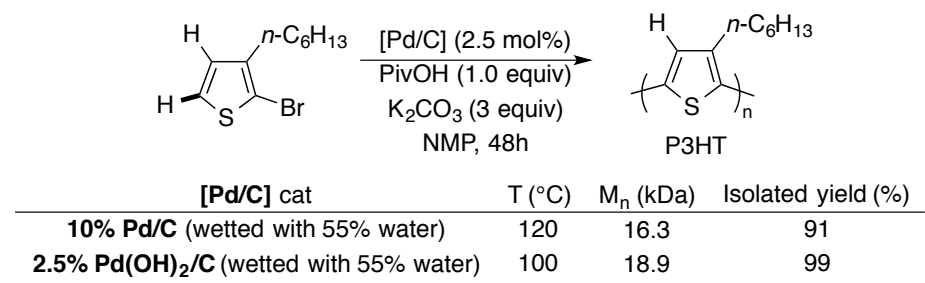

Scheme 30. Polycondensation of thiophenes in the presence of heterogeneous $\mathrm{Pd} / \mathrm{C}$

Palladium nanoparticles embedded in spherical polypyrrole globules have been successfully used by Hierso and co-workers for the direct arylation of 2butylfuran or 2-butylthiophene with activated or deactivated electron-poor and electron-rich functionalized bromoarenes (Scheme 31)[41].

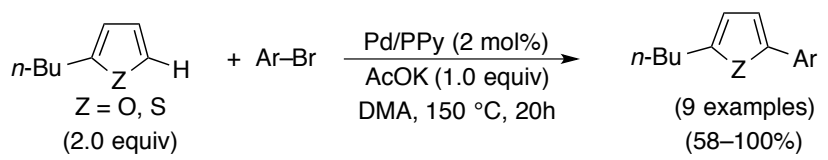

Ar-Br:<smiles>Pc1ccc(Br)cc1</smiles>

$\mathrm{R}=\mathrm{H}, \mathrm{CN}, \mathrm{COMe}$<smiles>Cc1cccc(Br)c1</smiles><smiles>Cc1cc(C)c(Br)c([N+](=O)[O-])c1</smiles>

Scheme 31. Direct C5 arylation of 2-butylfuran and 2-butylthiophene promoted by Pd/PPy The catalyst was recovered by simple filtration, but recycling tests were successfull only for few substrates. This was due to a growth of the particles size after the first cycle, which dramatically reduces the catalyst activity.

\section{Mild protocols for the direct arylation of heteroarenes}

One issue of direct arylation procedures is represented by the need for drastic conditions, elevated temperatures (from $110^{\circ} \mathrm{C}$ up to $160^{\circ} \mathrm{C}$ and higher when microwave irradiation is employed) and long reaction times (24 to $48 \mathrm{~h}$ and more are common). 
To solve this problem, Larrosa and Lebrasseur proposed a new approach for the direct $\mathrm{C} 2$ arylation of indoles with aryl iodides at room temperature without phosphines or other ligands[42]. The key features of this protocol were the combined use of $\mathrm{Ag}_{2} \mathrm{O}$ as the base, which enabled the formation of an electrophilic cationic palladium complex, and ortho-nitrobenzoic acid, which generates in situ a silver carboxylate particularly effective in promoting a CMD mechanistic pathway (Scheme 32).

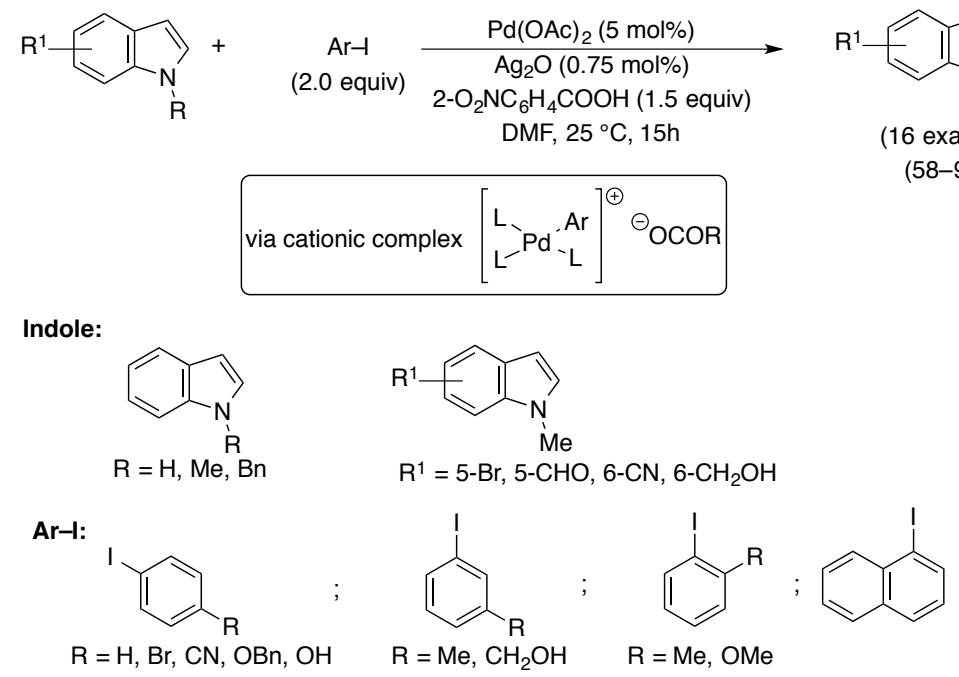

Scheme 32. Room temperature direct $\mathrm{C} 2$ arylation of indoles

All the reactions were performed at $25^{\circ} \mathrm{C}$, except for the direct arylation involving free- $\mathrm{NH}$ indole, which required $38 \mathrm{~h}$ at $50{ }^{\circ} \mathrm{C}$ to go to completion $(68 \%$ isolated yield). The authors said that both a $\mathrm{P}(0) / \mathrm{Pd}(\mathrm{II})$ or a $\mathrm{Pd}(\mathrm{II} / \mathrm{Pd}(\mathrm{IV})$ catalytic cycle are conceivable even if they propended for the first mechanistic pathway. An important specificity for solvent was also found: DMF, an highly cooordinating solvent, resulted superior (95\% yield) to $\mathrm{CH}_{2} \mathrm{Cl}_{2}(27 \%), \mathrm{MeCN}$ (14\%), AcOH (50\%), and DMA (50\%).

A similar approach, i.e. the use of a $\operatorname{Ag}(\mathrm{I})$ base to promote the formation of an active cationic $\mathrm{Pd}(\mathrm{II})$ complex, allowed the direct arylation of some halothiophenes at only $60{ }^{\circ} \mathrm{C}$ using an unusual biphasic AcOEt $/ \mathrm{H}_{2} \mathrm{O}(2.5: 1)$ solvent system (Scheme 33)[43]

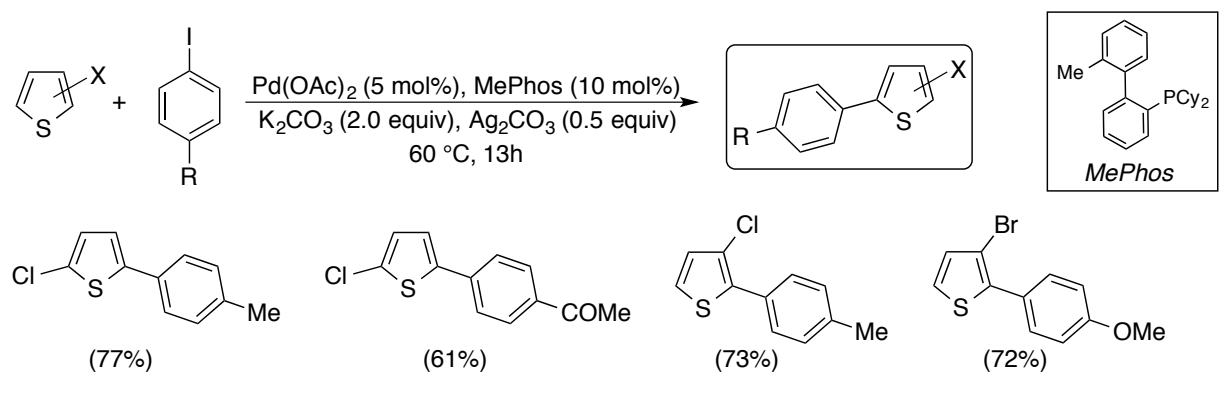

Scheme 33. Mild direct arylation of halothiophenes 
It is interesting to note that 3-halothiophenes led regioselectively to the 2-arylated derivatives, and that $\mathrm{C}$ - $\mathrm{Br}$ bonds of 3-bromothiophene resulted unreactive under this mild reaction conditions.

The use of $\operatorname{Ag}(\mathrm{I})$ salts to promote direct arylations was proved to be successfull also employing an "on water" approach. Several 2-arylindoles were obtained in high yields by reacting the corresponding indoles with aryl iodides in neat water at $30{ }^{\circ} \mathrm{C}$ for $16 \mathrm{~h}$ in the presence of $c-\mathrm{C}_{6} \mathrm{H}_{11} \mathrm{CO}_{2} \mathrm{Ag}$ (1.5 equiv) (Scheme 34) [44]. Notably, the reaction did not work when free-NH indole was employed.

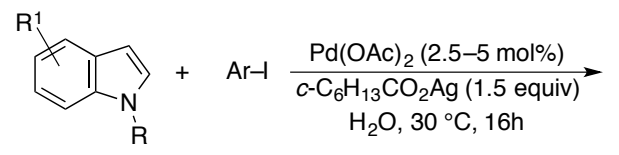

$\mathrm{R}=\mathrm{Me}, \mathrm{SEM}, \mathrm{Bn}, \mathrm{TBDMS}, \mathrm{CO} t-\mathrm{Bu}, \mathrm{Boc}, \mathrm{Ts}$

$\mathrm{R}^{1}=\mathrm{H}, 5-\mathrm{OBn}, 5-\mathrm{CHO}, 5-\mathrm{OMe}, 5-\mathrm{Cl}, 5-\mathrm{Br}, 5-\mathrm{NO}_{2}, 6-\mathrm{CH}_{2} \mathrm{OH}, 6-\mathrm{F}, 6-\mathrm{COOMe}$, 6-CN, 7-Br, 3-Me, 3-Ph

$\mathrm{Ar}=4-\mathrm{MeC}_{6} \mathrm{H}_{4}, 4-\mathrm{MeOCC}_{6} \mathrm{H}_{4}, 4-\mathrm{MeOOCC}_{6} \mathrm{H}_{4}, 4-\mathrm{MeOC}_{6} \mathrm{H}_{4}, 3-\mathrm{F}_{3} \mathrm{CC}_{6} \mathrm{H}_{4}$, 2- $\mathrm{MeOC}_{6} \mathrm{H}_{4}, 2-\mathrm{MeC}_{6} \mathrm{H}_{4}$, 2-naphthyl, $\mathrm{N}$-methyl-5-indolyl

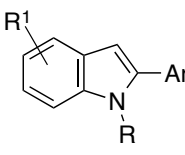

(32 examples) (25-99\%)

Scheme 34. Mild direct arylation of indoles "on water"

In 2013 a mild, general and convenient phopshine-free direct arylation of 1methylpyrazole, oxazole and thiazole promoted by tetrabutylammonium acetate $\left(\mathrm{Bu}_{4} \mathrm{NOAc}\right)$ was developed by Bellina and co-workers[45]. Electron-poor and electron-rich aryl bromides were find to react at only $70^{\circ} \mathrm{C}$ in DMA, allowing the isolation of the corresponding 5-substituted azoles in good yields (Scheme 35).

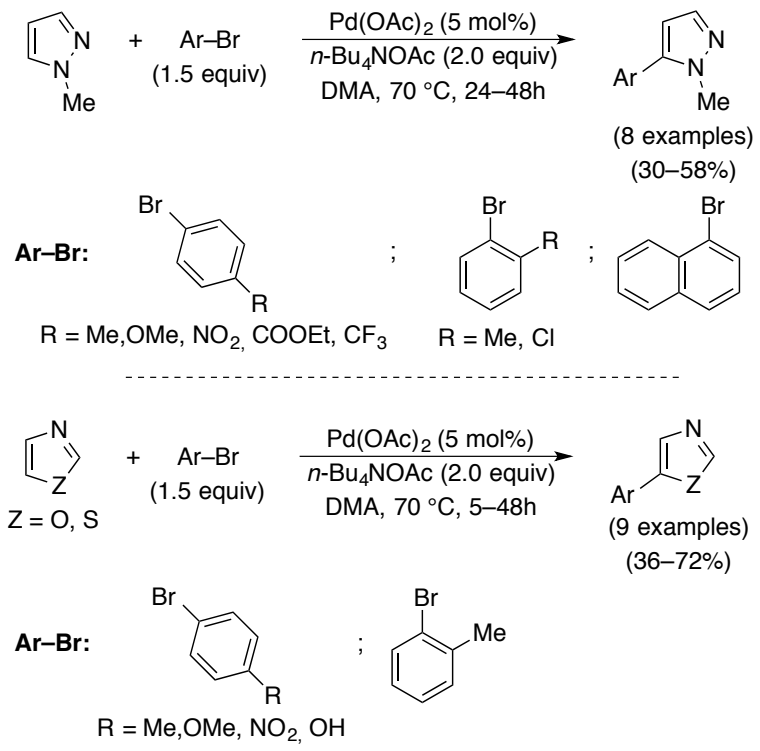

Scheme 35. Mild direct $\mathrm{C} 5$ arylation of azoles promoted by $\mathrm{Bu}_{4} \mathrm{NOAc}$

This protocol, paired with the regioselective direct $\mathrm{C} 2$ arylation of azoles mediated by palladium and copper, was applied to the synthesis of the natural products balsoxin and texalin through a one-pot sequential C5-C2 double 
arylation[45] and, more recently, to the preparation of several imidazole analogues of resveratrol able to reduce the growth of human tumor cell lines[46].

\section{Conclusions}

The methods of palladium-catalyzed direct arylation of heteroarenes with (hetero)aryl halides displayed an exponential growth in less than 20 years. Several significant progresses have been done since 1998, when Miura and co-workers published their seminal paper in which they describe for the first time the role of the base and of the catalyst in the activation of heteroaryl C-H bonds[47]. As summarized in this account, methods have been developed to react cheap aryl chlorides instead of the more expensive bromides or iodides; heterogeneous palladium catalysts have been employed in order to reduce metal waste and to allow recycling; procedures for lowering the reaction temperature have been set up, and removable functional group have been selected to increase the efficiency and the regioselectivity of the direct arylations. Many efforts should be done, however, in further improving the regioselectivity of the process, in order to reduce or eliminate the need for chromatographic purifications in view of processes scale-up and industrial applications, and also to increase the catalyst efficiency with the aim of widening the substrate scope.

1. Horton DA, Bourne GT, Smythe ML (2003) Chem Rev 103: 893. doi:10.1021/cr020033s

2. aJiang W, Li Y, Wang Z (2013) Chem Soc Rev 42: 6113. doi:10.1039/c3cs60108k; bMercier LG, Leclerc M (2013) Acc Chem Res 46: 1597. doi:10.1021/ar3003305

3. Hassan J, Sévignon M, Gozzi C, Schulz E, Lemaire M (2002) Chemical Reviews 102: 1359. doi:10.1021/cr000664r

4. aTorborg C, Beller M (2009) Advanced Synthesis \& Catalysis 351: 3027.

doi:10.1002/adsc.200900587; bCorbet JP, Mignani G (2006) Chem Rev 106: 2651. doi:10.1021/cr0505268 5. aHussain I, Singh T (2014) Advanced Synthesis \& Catalysis 356: 1661.

doi:10.1002/adsc.201400178; bRossi R, Bellina F, Lessi M, Manzini C (2014) Advanced Synthesis \& Catalysis 356: 17. doi:10.1002/adsc.201300922; cYamaguchi J, Yamaguchi AD, Itami K (2012) Angew Chem Int Ed Engl 51: 8960. doi:10.1002/anie.201201666

6. Nakamura N, Tajima Y, Sakai K (1982) Heterocycles 17: 235.

7. Littke AF, Fu GC (2002) Angew Chem Int Ed Engl 41: 4176. doi:10.1002/1521-

3773(20021115)41:22<4176::AID-ANIE4176>3.0.CO;2-U

8. Campeau LC, Thansandote P, Fagnou K (2005) Org Lett 7: 1857. doi:10.1021/o1050501v

9. Leblanc M, Fagnou K (2005) Org Lett 7: 2849. doi:10.1021/o10505959

10. Campeau LC, Parisien M, Jean A, Fagnou K (2006) J Am Chem Soc 128: 581.

doi:10.1021/ja055819x

11. Leclerc JP, Fagnou K (2006) Angew Chem Int Ed Engl 45: 7781. doi:10.1002/anie.200602773 
12. Gottumukkala AL, Doucet H (2007) European Journal of Inorganic Chemistry 2007: 3629. doi:10.1002/ejic.200700420

13. Sharma A, Vacchani D, Van der Eycken E (2013) Chemistry 19: 1158. doi:10.1002/chem.201201868

14. Iwasaki M, Yorimitsu H, Oshima K (2007) Chem Asian J 2: 1430. doi:10.1002/asia.200700206

15. Ackermann L, Vicente R, Born R (2008) Advanced Synthesis \& Catalysis 350: 741.

doi:10.1002/adsc. 200800016

16. Chiong HA, Daugulis O (2007) Org Lett 9: 1449. doi:10.1021/o10702324

17. Roy D, Mom S, Beaupérin M, Doucet H, Hierso J-C (2010) Angewandte Chemie 122: 6800. doi:10.1002/ange.201002987

18. Strotman NA, Chobanian HR, Guo Y, He J, Wilson JE (2010) Org Lett 12: 3578. doi:10.1021/ol1011778

19. Tamba S, Okubo Y, Tanaka S, Monguchi D, Mori A (2010) J Org Chem 75: 6998. doi:10.1021/jo101433g

20. Kumar PV, Lin W-S, Shen J-S, Nandi D, Lee HM (2011) Organometallics 30: 5160. doi:10.1021/om200490k

21. Nadres ET, Lazareva A, Daugulis O (2011) J Org Chem 76: 471. doi:10.1021/jo1018969

22. Liu B, Wang Z, Wu N, Li M, You J, Lan J (2012) Chemistry 18: 1599.

doi:10.1002/chem.201103329

23. Ghosh D, Lee HM (2012) Org Lett 14: 5534. doi:10.1021/ol302635e

24. Shen XB, Zhang Y, Chen WX, Xiao ZK, Hu TT, Shao LX (2014) Org Lett 16: 1984. doi:10.1021/o1500531m

25. Bellina F, Cauteruccio S, Rossi R (2006) Eur J Org Chem: 1379. doi:10.1002/ejoc.200500957

26. Rieth RD, Mankad NP, Calimano E, Sadighi JP (2004) Org Lett 6: 3981. doi:10.1021/o1048367m

27. aCampeau LC, Bertrand-Laperle M, Leclerc JP, Villemure E, Gorelsky S, Fagnou K (2008) J Am Chem Soc 130: 3276. doi:10.1021/ja7107068; bCampeau LC, Stuart DR, Leclerc JP, Bertrand-Laperle M, Villemure E, Sun HY, Lasserre S, Guimond N, Lecavallier M, Fagnou K (2009) J Am Chem Soc 131: 3291. doi:10.1021/ja808332k; cHuestis MP, Fagnou K (2009) Org Lett 11: 1357. doi:10.1021/o1900150u

28. Yan G, Borah AJ, Yang M (2014) Advanced Synthesis \& Catalysis 356: 2375. doi:10.1002/adsc.201400203

29. Goikhman R, Jacques TL, Sames D (2009) J Am Chem Soc 131: 3042. doi:10.1021/ja8096114

30. Joo JM, Toure BB, Sames D (2010) J Org Chem 75: 4911. doi:10.1021/jo100727j

31. Joo JM, Guo P, Sames D (2013) J Org Chem 78: 738. doi:10.1021/jo3021677

32. Chen L, Roger J, Bruneau C, Dixneuf PH, Doucet H (2011) Chem Commun (Camb) 47: 1872. doi: $10.1039 / \mathrm{c} 0 \mathrm{cc} 04302 \mathrm{~h}$

33. Flegeau EF, Popkin ME, Greaney MF (2008) Org Lett 10: 2717. doi:10.1021/o1800869g

34. Liegault B, Petrov I, Gorelsky SI, Fagnou K (2010) J Org Chem 75: 1047. doi:10.1021/jo902515z

35. Derridj F, Roger J, Djebbar S, Doucet H (2010) Org Lett 12: 4320. doi:10.1021/ol101758w

36. Djakovitch L, Felpin F-X (2014) ChemCatChem 6: 2175. doi:10.1002/cctc.201402288

37. Cusati G, Djakovitch L (2008) Tetrahedron Letters 49: 2499. doi:10.1016/j.tetlet.2008.02.130

38. Huang Y, Lin Z, Cao R (2011) Chemistry 17: 12706. doi:10.1002/chem.201101705

39. Parisien M, Valette D, Fagnou K (2005) J Org Chem 70: 7578. doi:10.1021/jo051039v

40. Hayashi S, Kojima Y, Koizumi T (2015) Polym. Chem. 6: 881. doi:10.1039/c4py01426j

41. Zinovyeva VA, Vorotyntsev MA, Bezverkhyy I, Chaumont D, Hierso J-C (2011) Advanced Functional Materials 21: 1064. doi:10.1002/adfm.201001912

42. Lebrasseur N, Larrosa I (2008) J Am Chem Soc 130: 2926. doi:10.1021/ja710731a 
43. Rene O, Fagnou K (2010) Org Lett 12: 2116. doi:10.1021/ol1006136

44. Islam S, Larrosa I (2013) Chemistry 19: 15093. doi:10.1002/chem.201302838

45. Bellina F, Lessi M, Manzini C (2013) European Journal of Organic Chemistry 2013: 5621.

doi:10.1002/ejoc.201300704

46. Bellina F, Guazzelli N, Lessi M, Manzini C (2015) Tetrahedron 71: 2298.

doi:10.1016/j.tet.2015.02.024

47. Pivsa-Art S, Satoh T, Kawamura Y, Miura M, Nomura M (1998) Bulletin of the Chemical Society of Japan 71: 467. doi:10.1246/bcsj.71.467 